\author{
UNIVERSIDADE DE SÃO PAULO \\ FACULDADE DE ZOOTECNIA E ENGENHARIA DE ALIMENTOS
}

GABRIELA MARQUES MARCILLI

Avaliação da associação entre microbioma fecal e eficiência alimentar em bovinos da raça Angus 
GABRIELA MARQUES MARCILLI

Avaliação da associação entre microbioma fecal e eficiência alimentar em bovinos da raça Angus

Versão corrigida

Dissertação apresentada à Faculdade de Zootecnia e Engenharia de Alimentos da Universidade de São Paulo, como parte dos requisitos para a obtenção do titulo de Mestre em Ciências do programa de Pós-Graduação em Biociência Animal.

Área de Concentração: Genética, Biologia Molecular e Celular

Orientador: Prof. Dr. Heidge Fukumasu 
Ficha catalográfica elaborada pelo

Serviço de Biblioteca e Informação,

FZEA/USP, com os dados fornecidos pelo(a)

autor (a)

Marques Marcilli, Gabriela

Avaliação da associação entre microbioma fecal e eficiência alimentar em bovinos da raça Anugus /

Gabriela Marques Marcilli ; orientador Heidge

Fukumasu ; coorientador José Bento Sterman Ferraz. -

- Pirassununga, 2019.

$72 \mathrm{f}$.

Dissertação (Mestrado - Programa de Pós-Graduação em Biociência Animal) -- Faculdade de Zootecnia e Engenharia de Alimentos, Universidade de São Paulo.

1. Gado de corte. 2. Consumo alimentar residual. 3. Metagenômica. 4. Bacteria. 5. Arquéia. I. Fukumasu, Heidge, orient. II. Ferraz, José Bento Sterman, coorient. III. Título. 


\title{
Avaliação da associação entre microbioma fecal e eficiência alimentar em bovinos da raça Angus
}

\begin{abstract}
Dissertação apresentada à Faculdade de Zootecnia e Engenharia de Alimentos da Universidade de São Paulo, como parte dos requisitos para a obtenção do titulo de Mestre em Ciências do programa de Pós-Graduação em Biociência Animal.
\end{abstract}

Data de aprovação: 18/09/2019

Banca Examinadora:

Prof. Dr. Heidge Fukumasu

Faculdade de Zootecnia e Engenharia de Alimentos - Universidade de São Paulo Presidente da Banca Examinadora

Dr. Ivan Glaucio Paulino Lima

Blue Marble Space Institute of Science - BMSIS/NASA

Prof. Dr. Miguel Henrique de Almeida Santana

Faculdade de Zootecnia e Engenharia de Alimentos - Universidade de São Paulo

Prof. Dr. Rodrigo Silva Goulart

Faculdade de Zootecnia e Engenharia de Alimentos - Universidade de São Paulo 


\section{AGRADECIMENTOS}

À minha família por todo apoio e suporte durante o desenvolvimento deste trabalho.

Ao professor Heidge pela orientação. Por ter me escolhido para este projeto e ter acreditado na minha capacidade e principalmente pela paciência e por estar sempre presente. Agradeço pela oportunidade de desenvolver um projeto tão proveitoso tanto para o crescimento pessoal quanto como contribuição para a sociedade.

Ao professor José Bento, pela coorientação. Por ser um elemento fundamental na obtenção de amostras e por ser minha porta de entrada para a FZEA sem o qual o desenvolvimento deste projeto seria imensuravelmente mais penoso.

Ao melhor trio de amigos que se tornou uma família pra vida toda nesse curto tempo de convivência Dri, Manu e Mel. Por estarem sempre presente nas risadas e nos choros, nas comemorações e nos perrengues e tornar essa caminhada muito mais leve.

À Priscila, pelo auxílio nas coletas e nas análises estatísticas e pela enorme paciência com a minha ansiedade, e também pela amizade fora na universidade.

À republica Curva de Rio pelo acolhimento e momentos de extrema alegria, onde descobri irmãs pra uma vida toda.

À professora Rachel pela oportunidade de ser aluna PAE e ter uma pequena noção de como é a vida de docente. Pelos conselhos pessoais e pelas contribuições profissionais.

Aos alunos da turma da Zoo 39 pelo imenso carinho que demonstraram durante as disciplinas em que fui monitora e que continua até hoje.

Aos colegas do GMA que de alguma forma contribuíram para o meu crescimento. Em especial à Elisângela que resolveu muitos imprevistos durante essa jornada, sempre de boa vontade e com bom humor; e a Dona Vera que muito mais que uma funcionária se tornou praticamente uma mãe (mãe jovem), dando bronca, contando das novelas e fazendo o melhor chá de erva cidreira.

Aos colegas do LOCT me ajudaram no desenvolvimento e nas análises e pelas críticas construtivas que contribuíram para esse trabalho Tais, Roberta, Pâmela, Pedro, Pedrinho, Jé e aos demais colegas. Às meninas que me ajudaram 
nas coletas Alana e Roberta C. e às fadas sensatas pelos momentos de crise existencial compartilhada Gabi, Raquel e Mary e Sacha.

À Arina, que muito mais do que uma técnica de laboratório, me auxiliou em todas as etapas, desde conselhos para a vida pessoal, até todos os ensinamentos repassados, a qual eu devo tudo que aprendi dentro laboratório. E pelos momentos baladas e técnicas de futebol também, claro.

À todos os funcionários e amigos dos setores por onde passei, suinocultura, confinamento e laboratórios, ao Dione que eu fiquei devendo um bolo.

À Agropecuária Verdana Angus pelas amostras cedidas e pela assessoria.

À Polyana pelo auxilio com as análises.

Aos amigos aos quais me tornei mais próxima durante este tempo Carol, Gab, Dan, Garga, Aska, Laurinha, Lina, Camilla e Hooper.

À todos os amigos que encontrei dentro e fora da universidade, nessa cidade simpatia, e que me ajudaram das mais diversas formas, desde correções e dicas profissionais à colheita de jabuticaba e aventuras paranormais, e que levarei para vida toda e aos quais peço desculpa se não consegui mencionar à todos por serem muitos, felizmente.

À Faculdade de Zootecnia e Engenharia de Alimentos e ao Programa de Pós-Graduação em Biociência Animal da USP pela oportunidade de me formar Mestre em Ciências. 
"E aqueles que foram vistos dançando foram julgados insanos por aqueles que não podiam ouvir a música"

Friedrich Nietzsche 
RESUMO

MARCILLI, G. M. Avaliação da associação entre microbioma fecal e eficiência alimentar em bovinos da raça Angus. 73 f. Dissertação (Mestrado) - Faculdade de Zootecnia e Engenharia de Alimentos, Universidade de São Paulo, Pirassununga, 2019.

A eficiência alimentar (EA) é uma característica de grande importância para a sustentabilidade do sistema de produção animal. Animais eficientes apresentam melhor aproveitamento de alimentos e redução considerável na emissão de gases poluentes, diminuindo o impacto ambiental da pecuária. Contudo, a EA é uma característica de difícil mensuração. Com a crescente evidência de que hospedeiros e seus microbiomas interagem em associações complexas, o objetivo dessa pesquisa foi avaliar a associação entre o microbioma fecal e a eficiência alimentar em bovinos da raça Angus (Bos taurus). Foram utilizadas amostras de fezes de 64 animais mensurados quanto à ingestão de matéria seca (IMS), conversão alimentar (CA), consumo alimentar residual (CAR), ganho de peso diário (GMD) e características de carcaça. As amostras tiveram DNA total extraído e foram identificados os perfis de bactérias e arquéias presentes e suas possíveis relações com a EA a partir do sequenciamento de regiões específicas do gene 16s. Além disso, foram selecionados animais de alta eficiência alimentar $(A E A, n=15)$ e baixa eficiência alimentar (BEA, $n=15)$, pela medida de CAR, que tiveram os dados de microbioma comparados entre os dois grupos. Foi observado que os grupos de $A E A$ e BEA apresentaram desempenho igual quanto ao ganho de peso, características de carcaça. Por outro lado, os animais de BEA tiveram maior consumo de alimentos e também apresentaram maior presença de micro-organismos metanogênicos. Com base em estudos anteriores e nos resultados encontrados neste estudo criou-se a hipótese de que animais divergentes para eficiência alimentar podem apresentar diferenças no microbioma fecal que podem ser utilizadas como uma forma de se identificar animais superiores para essa característica nos levando a uma melhor compreensão dos mecanismos envolvidos na EA.

Palavras-chave: Gado de corte, consumo alimentar residual, metagenômica, bactéria, arquéia, metanogênica 


\section{ABSTRACT}

\section{MARCILLI, G. M. Evaluation of the association betweeen fecal microbiome and}

feed efficiency in Angus cattle. 73 f. M.Sc. Dissertation - Faculdade de Zootecnia e Engenharia de Alimentos, Universidade de São Paulo, Pirassununga, 2019.

Feed efficiency (FE) is a phenotype of great importance for the sustainability of the livestock production system. Efficient animals have better use of food and considerable reduction in greenhouse gas emissions, reducing the environmental impact of livestock. However, FE is a trait difficult to measure. With increasing evidence that the hosts and their microbiomes interact in complex associations, the aim of this study was to evaluate the association between fecal microbiome and feed efficiency in Angus cattle (Bos taurus). Stool samples from 64 animals with phenotype for dry matter intake (DMI), feed conversion ratio (FCR), residual feed intake (RFI), average daily gain (ADG) and carcass characteristics were used. The samples had total DNA extracted and the profiles of bacteria and Arquéia and their possible relationship with EA were identified. In addition, animals with high feed efficiency (HFE, $n=15$ ) and low feed efficiency (LFE, $n=15$ ) were selected by RFI measurement, which had microbiome data compared between the two groups. It was observed that the HFE and LFE groups presented equal performance regarding weight gain and carcass traits. On the other hand, the animals from LFE had higher feed intake and presented higher presence of methanogenic microorganisms. Based on previous studies and the results found in this research, it was hypothesized that animals differing in feed efficiency may present differeces in fecal microbiome that can be used as a way to identify superior animals for this trait. We believe this is a pioneer result in beef cattle that can lead us to a better understanding of the mechanisms involved in FE.

Key-words: Beef cattle, residual feed intake, metagenomics, bacteria, Arquéia, methanogenics 
1. INTRODUÇÃO

2. REVISÃO DE LITERATURA

2.1. Definindo a eficiência alimentar em bovinos de corte .............................10

2.2. A importância do microbioma para a eficiência alimentar .........................13

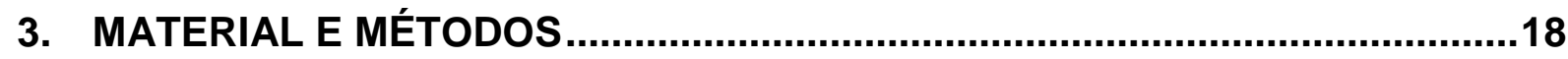

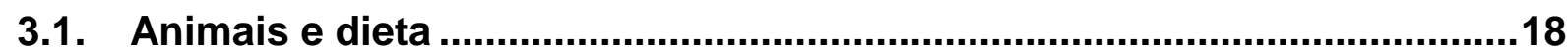

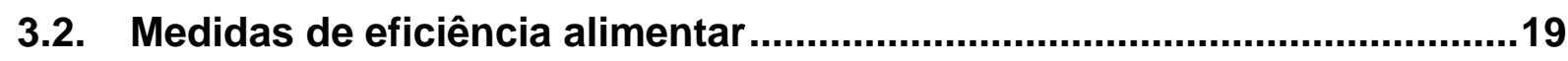

3.3. Avaliação de carcaça por ultrassonografia.............................................19

3.4. Coleta de amostras biológicas e extração de DNA ………........................19

3.5. Preparo de Bibliotecas e Sequenciamento …............................................20

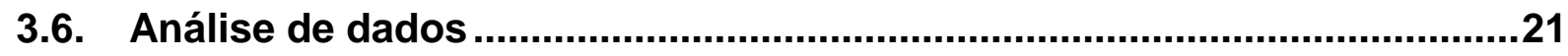

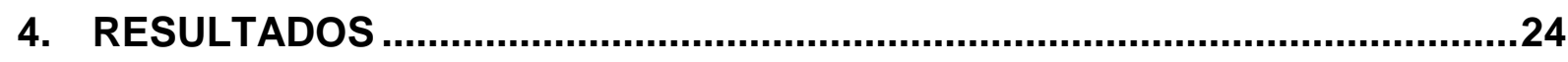

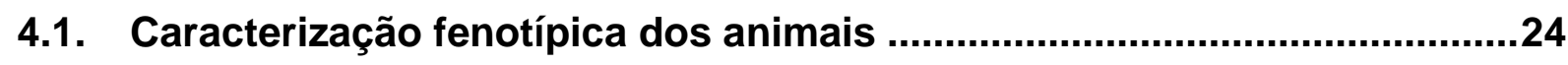

4.2. Caracterização dos grupos de alta e baixa eficiência alimentar ...............26

4.3. Caracterização dos dados de sequenciamento ...........................................28

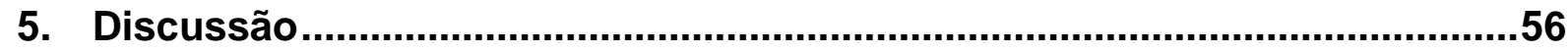

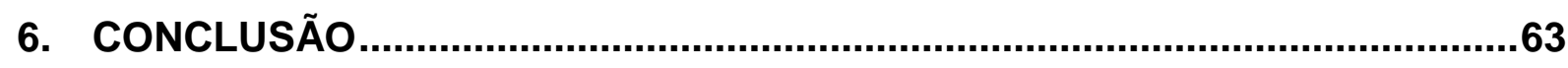

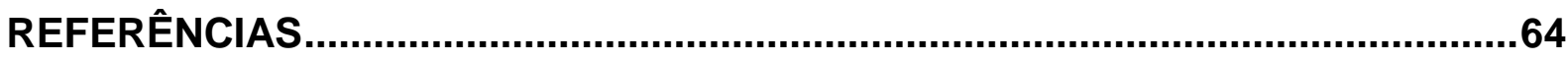




\section{INTRODUÇÃO}

O constante crescimento da população mundial juntamente com a necessidade em suprir a demanda por alimento e ao mesmo tempo diminuir o impacto ambiental da pecuária constituem novos desafios e objetivos para a seleção animal. Identificar indivíduos que processem seus alimentos de forma mais eficiente e apresentem maior aproveitamento em alimentos de baixa qualidade, e reduzir a produção de dejetos e a intensidade de emissão de gases de efeito estufa, consequentemente diminuindo o impacto ambiental da pecuária são algumas das características que podem ser alcançadas através da seleção para alta eficiência alimentar (EA). Animais superiores quanto a essa característica possuem níveis de produção similares aos demais, porém apresentam menor consumo. Dessa forma, além de poluírem menos e serem mais produtivos, convertendo melhor o alimento em carne, esses animais também promovem um aumento na lucratividade do sistema, uma vez que as despesas com alimentação representam a maior porcentagem no custo de produção.

Como mencionado anteriormente, o termo eficiência alimentar envolve uma relação entre consumo e produção de alimentos e uma das formas para defini-la é através do consumo alimentar residual (CAR). Uma equação de regressão linear fenotípica é usada para estimar a ingestão esperada de alimento de um animal com base em seu peso e taxa de crescimento ao longo de um determinado período de teste. A diferença entre a ingestão observada e a ingestão estimada é chamada de CAR. Animais eficientes são aqueles que consomem menos alimento do que o esperado e apresentam CAR negativo.

Ainda que se mostre uma característica de grande importância, um dos impasses do uso da eficiência alimentar é sua mensuração lenta e onerosa e a dificuldade de usa-la para bovinos de corte principalmente em sistemas extensivos de produção. Ademais, a EA é considerada uma característica poligênica que pode ser influenciada por diferentes processos biológicos de difícil compreensão. Neste sentido, novas tecnologias têm sido desenvolvidas para identificar animais superiores de forma mais precoce.

Diversos estudos têm evidenciado que hospedeiros e seus microbiomas interagem em associações complexas acerca do processamento dos alimentos e 
aproveitamento dos nutrientes da dieta e investigar a variação na população de micro-organismos ao longo do trato gastrointestinal (TGI) pode nos levar a uma melhor compreensão dos mecanismos microbiológicos e moleculares envolvidos nessa eficiência de utilização dos alimentos. Os estudos de microbioma do rúmen e dos demais seguimentos do TGI identificam e classificam conjuntos de bactérias, fungos e vírus que compõem um organismo e que diferem consideravelmente de um animal para outro. Entretanto, o conhecimento da diversidade microbiana dependente de técnicas tradicionais de cultivo é limitado. Um dos principais problemas é o estabelecimento de meios e condições de cultivo compatíveis com o ambiente natural dos micro-organismos.

As chamadas tecnologias "ômicas", que são tecnologias voltadas para a genética molecular, têm sido acentuadas nas últimas décadas e trazem ferramentas inovadoras que permitem uma melhor compreensão da relação genótipo e fenótipo que influenciam determinadas características. Dentre elas, destacamos a metagenômica que tem sido a abordagem mais utilizada para contornar as limitações técnicas dependentes do cultivo nos permitindo o estudo do material genético recuperado diretamente a partir de amostras ambientais. Essa estratégia tem demonstrado não só uma riqueza na diversidade de organismos como também o potencial funcional da comunidade microbiana já que o estudo do genoma permite a descoberta de novos genes e vias metabólicas.

Outra dificuldade encontrada nesse tipo de estudo é a complexidade na coleta de amostras. Coletar amostras de material do rúmen ou de qualquer outra fração do TGI sem a necessidade de abater os animais e sem risco de contaminação de outros micro-organismos externos exige técnicas mais onerosas e um tanto quanto invasivas e estressantes ao animal como a utilização de sondas e/ou fístulas.

Deste modo, o objetivo deste trabalho foi caracterizar a eficiência alimentar em bovinos da raça Angus (Bos taurus) através de medidas de desempenho em confinamento e avaliar sua possível relação com o microbioma fecal, determinado através da metagenômica, a fim de identificar perfis específicos associados a esse fenótipo, possibilitando uma metodologia de avaliação menos invasiva e uma identificação precoce de indivíduos superiores. 


\section{REVISÃO DE LITERATURA}

\subsection{Definindo a eficiência alimentar em bovinos de corte}

A carne bovina representa um dos principais produtos do agronegócio brasileiro, estando presente em praticamente todos os estados. Segundo a ABIEC (2019), no ano passado o PIB da pecuária elevou para $8,7 \%$ sua participação no PIB total brasileiro, somando $\mathrm{R} \$ 597,22$ bilhões. O valor é o maior já registrado nos últimos dez anos. Atualmente o Brasil ocupa a primeira posição no ranking mundial de produtores e exportadores de carne bovina e estima-se um aumento nessa produção de 1.639 mil toneladas equivalente carcaça ou $1,9 \%$ ao ano para a próxima década, conseguindo atender ao consumo interno e às exportações (ABIEC, 2019; BRASIL, 2017). Para supri essa demanda e ao mesmo tempo mitigar os impactos ambientas da produção tem-se buscado identificar animais com maior eficiência alimentar.

A eficiência alimentar é uma característica para o quão bem o animal utiliza os nutrientes da alimentação para a produção. Depende de vários fatores como consumo de alimentos, o peso vivo do animal, estado fisiológico, composição do ganho de peso, condições ambientais, idade e fatores intrínsecos ligados à eficiência, isto é, taxas de digestão, absorção e eficiência de utilização da energia e proteína metabolizável. Ainda que se mostre uma característica de grande importância, um dos impasses do uso da eficiência alimentar é sua mensuração lenta e onerosa e a dificuldade de usa-la para bovinos de corte principalmente em sistemas extensivos de produção. Ademais, a EA é considerada uma característica poligênica que pode ser influenciada por diferentes processos biológicos de difícil compreensão. (WONFOR, 2017; ALEXANDRE et al., 2015).

Uma das formas para definir a EA é através do Consumo Alimentar Residual (CAR) proposto por Koch e colaboradores (1963). Uma equação de regressão linear fenotípica é usada para estimar a ingestão esperada de alimento de um animal com base em seu peso e taxa de crescimento ao longo de um determinado período de teste. A diferença entre a ingestão observada e a ingestão estimada é chamada de CAR. Animais eficientes são aqueles que consomem menos alimento do que o esperado e apresentam CAR negativo. Tais animais podem apresentar uma maior capacidade digestiva. Eles são capazes de utilizar mais energia da alimentação em 
vez de fracionar quantidades maiores a serem perdidas através de fezes. Por outro lado, animais ineficientes irão consumir mais alimentos do que o esperado e terão CAR positivo (WONFOR, 2017; CARSTENS; TEDESCHI, 2006).

Os parâmetros diretos da EA, dentre eles, ingestão de matéria seca (IMS), conversão alimentar (CA), consumo alimentar residual (CAR) e ganho de peso diário (GMD), exigem uma medição precisa do consumo de alimento e o ganho de peso para cada animal, por um período de 35 a 70 dias, o que demanda tempo, dinheiro, infraestrutura e mão de obra (ARCHER et al., 1997; BASARAB et al., 2013). Além disso, o CAR é difícil de calcular em um sitema extensivo, pois, a capacidade de realizar o cálculo com precisão para cada animal em um rebanho a pasto, é impraticável. Portanto, medidas alternativas tem sido estudadas, que possam ser usada na prática, seja ela um valor genético ou uma característica fenotípica (WONFOR, 2017).

A eficiência alimentar afeta diretamente a rentabilidade e a eficiência da produção e é um fator determinante para a sustentabilidade na indústria de carne bovina, uma vez que o custo dos alimentos poderia representar $50-70 \%$ das despesas brutas (COTTLE; KAHN, 2014). Com o uso do CAR, como critério, os animais podem ser selecionados por necessitarem de menos alimento para 0 mesmo nível de produção (BASARAB et al., 2003).

Além disso, a eficiência biológica de transformar os nutrientes do alimento em proteína muscular é muito menor no sistema de produção bovina (5\%) comparada ao de suíno (14\%) e ao de frango (21\%). Isso se deve principalmente ao custo energético associado à mantença (CARSTENS, 2001). Dessa forma, a rentabilidade de todo o sistema de produção de carne bovina depende da eficiência da utilização dos alimentos pelos animais. Fox, Guuiroy e Tedeschi (2001) constataram que uma melhora de 10\% na eficiência alimentar resultou em um acréscimo de $43 \%$ na rentabilidade. Sendo assim, o aumento da produção de carne por unidade de alimento consumida no sistema de produção total poderia ter potencial econômico na indústria da carne bovina.

Ademais, melhorar a EA é vantajoso não apenas do ponto de vista econômico, como também ambiental, reduzindo a emissão de gases poluentes e a competição por terras e grãos com a alimentação humana. Pode trazer um incremento significativo na redução na necessidade de áreas de pastagem para bovinos e em diversos índices de impacto ambiental, como emissão de carbono, de metano e 
produção de esterco (BASARAB et al., 2003; HAYES; LEWIN; GODDARD, 2013). Com o aumento da EA os animais apresentaram uma redução na produção de metano entérico $\left(\mathrm{CH}_{4}\right)$. O metano $\left(\mathrm{CH}_{4}\right)$ é o principal gás de efeito estufa (GEE) emitido por sistemas de produção de ruminantes, representando $12 \%$ a $17 \%$ das emissões de GEE (BEAUCHEMIN et al., 2009). A redução da emissão de $\mathrm{CH}_{4}$ do rebanho é uma necessidade para melhorar a pegada de carbono da produção de carne bovina, que varia de $17 \mathrm{~kg}$ de equivalentes de dióxido de carbono $\left(\mathrm{CO}_{2}\right) / \mathrm{kg}$ de carne de carcaça para bovinos terminados em confinamento no Canadá (VERGE et al., 2008; BEAUCHEMIN et al ., 2010; BASARAB et al., 2013) até $40 \mathrm{~kg}$ de $\mathrm{CO}_{2} / \mathrm{kg}$ de carne bovina acabada no Brasil (CEDERBERG et al., 2011).

A seleção genética para CAR é uma abordagem indireta para reduzir a emissão de metano entérico $\left(\mathrm{CH}_{4}\right)$ em gado de corte e leite. Segundo Herd e Arthur (2009), o CAR está correlacionado com produção de calor, de metano e com a digestibilidade dos alimentos, indicando que os animais mais eficientes, fenotipicamente, para o CAR tem menor requerimento de energia de mantença, menos produção de metano e uma melhora na digestibilidade. E dessa forma, produzem proporcionalmente menos poluentes (NKRUMAH et al., 2006). Myer e colaboradores (2017) observaram que a seleção para baixo CAR resultou em menor ingestão de matéria seca (IMS), tendo uma relação de conversão alimentar (CA) melhorada em comparação com animais de alto CAR, e produzindo $15 \%$ a $25 \%$ menos de $\mathrm{CH}_{4}$ entérico. Além disso, menor IMS, duração e frequência de alimentação e um perfil bacteriano diferente que melhora a fermentação do rúmen em animais eficientes podem favorecer uma melhora de $1 \%$ a $2 \%$ na digestibilidade de matéria seca proteína bruta em comparação com animais ineficientes (BASARAB et al., 2013). Do mesmo modo, Nkrumah e colaboradores (2006) encontraram que animais com baixo CAR produziram em média $28 \%$ menos gás metano do que aqueles com alto CAR, colaborando para a diminuição da emissão de gases poluentes, que também é um dos grandes problemas do setor. De acordo com Alford e colaboradores (2006) a criação de animais e seleção genética para a eficiência alimentar é o procedimento de mitigação mais prático, uma vez que é permanente e cumulativa.

Entender a causas da variação na eficiência alimentar irá ajudar na predição das possíveis respostas correlacionadas com a seleção do CAR, possibilitando mostrar indicadores mais fáceis e baratos de serem mensurados que o consumo e a eficiência alimentar (MÜLLER; LUETHOLD; REINECKE, 1995) tornando possível 
sugerir alternativas, que podem ser usadas para manipular o metabolismo bovino e, consequentemente, melhorar a eficiência alimentar (ARCHER et al., 1999). Animais ineficientes tendem a apresentar um maior gasto energético que animais eficientes. Dentre os fatores que podem interferir nos gastos energéticos dos animais estão associados a variação na quantidade de alimento ingerido pelos animais, digestão, metabolismo, atividade, e termorregulação (HERD; ODDY; RICHARDSON, 2004). Johnson et al. (2003) e Richardson \& Herd (2004) sugeriram que as fontes que podem contribuir para a variação no CAR são a ingestão e digestão dos alimentos, o aumento do calor, o turnover da proteína e o metabolismo geral do tecido, comportamento e atividade alimentar, composição corporal e taxa de ganho e peso vivo.

\subsection{A importância do microbioma para a eficiência alimentar}

Os ruminantes são completamente dependentes de sua microbiota para digestão dos alimentos e consequentemente sua viabilidade. Portanto é possível hipotetizar uma conexão entre a abundância e o perfil de micro-organismos residentes no TGI e os parâmetros fisiológicos do hospedeiro (Jami et al., 2014).

Estes animais são caracterizados pela sua fermentação anaeróbica pré-gástrica no rúmen, que abriga uma variedade de micro-organismo, incluindo bactérias, arqueias, protozoários e fungos. A associação destes atua de forma sinérgica para a conversão de celulose em ácidos graxos de cadeia curta (AGCCs) e proteínas que satisfazem as exigências de nutrientes dos animais (FREY et al., 2010).

Estudos comprovam que animais de mesmo tipo, recebendo a mesma dieta, podem apresentar variações na eficiência de utilização dos nutrientes (ARCHER et al., 1999). Um estudo recente descobriu que a capacidade digestiva representava até $31 \%$ da variação de CAR no gado leiteiro quando alimentado com uma dieta rica em fibras, mas não teve efeito nas dietas altas de amido (POTTS et al., 2017).

Animais selecionados para CAR apresentam diferenças metabólicas significativas (RICHARDSON; HERD, 2004; NKRUMAH et al., 2006). Essa variação está relacionada principalmente a diferenças nas perdas e retenção de energia na dieta (DELFINO; MATHISON, 1991; SAAMA; MAO, 1995; BASARAB et al., 2003). Ademais, pesquisas mostraram que existem diferenças genéticas entre os animais 
na capacidade de digestão de amido (CHANNON; ROWE; HERD, 2004) e metanogênese (NKRUMAH et al., 2006).

Com a crescente evidência de que os hospedeiros e seus microbiomas interagem em associações e redes complexas, examinar a variação da população de micro-organismos na eficiência alimentar pode levar a esclarecer parcialmente a variação considerável na eficiência da utilização de alimentos (FREY et al., 2010).

Foram identificados 19 filos bacterianos existentes, dentre eles Firmicutes, Bacteroidetes e Proteobacteria e gêneros de Prevotella, Bacteroides e Clostridia em maior número (BRULC et al., 2009). Muitos fatores podem afetar a diversidade, densidade e funções microbianas do rúmen, incluindo dieta, condições fisiológicas dos animais, estratégias de alimentação, nível de ingestão, e saúde animal, bem como tratamento médico (uso de antibióticos) (CARBERRY et al., 2012).

Dentro do microbioma ruminal, os diferentes tipos de micro-organismos apresentam diferentes especificidades como, por exemplo, as Acidaminococcus que são bactérias fermentadoras de aminoácidos e estão relacionadas à produção de butirato (COOK et al., 1994).

As Anaerovibrios têm sido associadas à produção de succinato e propionato, bem como a hidrólise lipídica e metabolismo em ruminantes (PRIVE et al., 2013). O filo Lentisphaerae também foi associado a mudanças na eficiência alimentar e as diferenças nas populações de Lentisphaerae foram observadas no rúmen durante a acidose subclinica (MAO et al., 2013).

Os Methanomassiliicoccales são um subconjunto de micro-organismos metanogênicos. A produção de metano está associada à ineficiência, pois sua produção no rúmen requer energia. Animais com baixa eficiência alimentar apresentam uma população mais diversificada de metanogênicos e utilizam mais energia para a metanogênese (ZHOU et al., 2009; KHIAOSAARD; ZEBELI, 2014). $\underline{\text { Succinivibrio } s p}$. foi associado à ingestão de matéria seca e ao ganho médio diário em animais eficientes.

A abundância de Robinsoniella sp. foi associada a animais de baixa EA, enquanto Eubacterium sp. diferiu entre os grupos de CAR quando alimentados com dieta de acabamento em confinamento (HERNANDEZ-SANABRIA et al., 2012).

Jami e colaboradores (2014) identificaram correlação positiva entre a abundância relativa das bactérias da ordem RF39 e o CAR em vacas leiteiras. E Myer et al. (2015) relataram que, embora Bacteroidetes e Firmicutes fossem os filos dominantes 
para ambos os grupos de CAR, a proporção de Succiniclasticum, Lactobacillus, Ruminococcus e Prevotella diferia entre os grupos de animais com ingestão variada de alimentos e ganho de peso corporal.

De acordo com Li e colaboradores (2016) o microbioma de animais com baixo CAR possui características associadas a maior função metabólica e capacidade de sobrevivência celular, sugerindo que a capacidade de fermentação e a capacidade de adaptação do microbioma podem ser fatores-chave para melhorar a disponibilidade de nutrientes, sendo um dos fatores biológicos associados à variação na eficiência da alimentação de bovinos.

Determinados micro-organismos podem estar associados a parâmetros de desempenho dos bovinos, incluindo ganho médio diário, ingestão de matéria seca, índice de conversão alimentar e CAR (GUAN et al., 2008; HERNANDEZ-SANABRIA et al., 2010). Guan et al. (2008) investigaram os perfis microbianos no rúmen de bovinos diferentes para EA e a análise indicou que grupos específicos de bactérias podem habitar apenas em animais eficientes, revelando associações potenciais entre a microbiota detectável do rúmen e seus parâmetros de fermentação com a eficiência alimentar bovina.

$\mathrm{Li}$ et al., 2016 encontraram diferenças em três famílias bacterianas, Lachnospiraceae, Veillonellaceae e Methanomassiliicoccales entre animais com alto e baixo CAR. Lachnospiraceae tem sido associado à eficiência alimentar e características de fermentação em bovinos de corte (HERNANDEZ-SANABRIA et al., 2010). Os resultados mostraram que o grupo de alto CAR possuía uma maior abundância relativa de Lachnospiraceae e maior abundância de Veillonellaceae sugerindo que os processos de redução de lactato podem ser mais rápidos em animais ineficientes. A maior abundância de Methanomassiliicoccales no grupo de baixo CAR indicou que mais metilaminas podem ser utilizadas durante a fermentação em animais eficientes.

Zhou et al. (2009) propuseram que as variadas preferências de substrato de metanogênese podem ser um dos mecanismos que conduzem à variação na produção de $\mathrm{CH}_{4}$ entre animais de alto e baixo CAR. A capacidade de utilizar um grupo metila dos substratos de metanogênese pode levar à variação de energia ou compostos disponíveis e afetar a CAR do hospedeiro.

Myer et al. (2015) constataram um aumento na abundância de Firmicutes, alterando a relação Firmicutes-Bacteroidetes, que afeta a absorção de energia e foi 
correlacionada com aumento de gordura. De acordo com os autores, o aumento nos Firmicutes e muitos dos gêneros pertencentes ao filo foram correlacionados com alto ganho de peso. Foi relatada menor diversidade e maior dominância na composição taxonômica aparente nos microbiomas de animais eficientes e o contrário pode ser observado para o grupo de alto CAR (KANEHISA et al., 2011; SHABAT et al., 2016).

Nos animais de menor eficiência alimentar, o uso mais diversificado de compostos como proteínas dietéticas, piruvato, acetil-CoA e hidrogênio, resultaram em um conjunto mais diversificado de metabólitos produzidos, alguns dos quais afetam a energia de forma negativa ou não pode ser utilizada pelo animal para seus requisitos de energia. Nos microbiomas dos animais eficientes, o uso desses compostos é dominado por um número limitado de caminhos metabólicos mais relevantes e valiosos para as necessidades energéticas do animal (SHABAT et al., 2016).

Os estudos anteriores se concentraram exclusivamente na avaliação do rúmen, principalmente, pois a produção de energia e o fornecimento de nutrientes ao animal em função da fermentação ruminal e da atividade da comunidade microbiana são considerados fundamentais para a eficiência da produção.

No entanto, não se pode esquecer que há todo um vasto microbioma ao longo do sistema digestivo que potencialmente tem relação com a eficiência alimentar tendo em vista a importância deste sistema para a obtenção e aproveitamento dos nutrientes. Isto é plenamente justificável uma vez que as capacidades funcionais e metabólicas dos segmentos do trato gastrointestinal (TGI) são distintas e contribuem para a saúde e o estado nutricional do animal.

Neste sentido, Myer et al (2017) analisaram o microbioma em diferentes pontos do sistema digestório em bovinos e buscaram relação à eficiência alimentar tendo encontrado os seguintes resultados: os grupos taxonômicos predominantemente representados no TGI foram dos filos Firmicutes e Bacteroidetes, que variaram muito dependendo da região; as populações de Bacteroidetes dominaram no rúmen, enquanto a Firmicutes foi o filo de maior abundância nos segmentos mais distais do TGl; no jejuno, Bacteroidetes estava em menor proporção e Firmicutes representaram mais de $80 \%$ dos filos; no rúmen, o gênero Prevotella constituiu mais de $90 \%$ da população de Bacteroidetes; as populações bacterianas do jejuno (especializado para a absorção de proteínas e carboidratos) eram radicalmente diferentes em comparação com o rúmen; as diferenças funcionais associadas entre 
os tecidos foram especialmente destacadas pela mudança de populações de Bacteroidetes dominantes no rúmen para Firmicutes dentro do jejuno, constituindo até $90 \%$ e; no rúmen, observou-se aumento significativo das abundâncias de Firmicutes no grupo de animais eficientes, apoiando a relação entre ganho e a proporção Firmicutes-Bacteroidetes.

Estes dados destacam as diferenças de diversidade filogenética entre as seções do TGI levantando a possibilidade de outros sítios microbianos serem relevantes à eficiência alimentar além do rúmen. Quando os animais se alimentam com dietas ricas em concentrado, quantidades substanciais de amido da dieta não sofrem fermentação ruminal e não são totalmente digeridos no intestino delgado, sendo fermentados no intestino grosso (IG). Essa segunda fermentação é semelhante à fermentação ruminal, com produção de AGCCs e queda do $\mathrm{pH}$ intestinal (DEPENBUSCH et al., 2008). A perda de metano e de calor faz da fermentação um processo menos eficiente, energeticamente, que a digestão enzimática (OWENS; ZINN; KIM, 1986).

Somada a esse fator, a proteína microbiana produzida no intestino grosso é eliminada nas fezes, pois não é absorvida, resultando em perda de proteínas que poderiam ser utilizada pelo animal. Os micro-organismos responsáveis por esta fermentação não são digeridos e absorvidos nesta região do TGI e são eliminados nas fezes. Sendo assim, com o aumento da fermentação dos carboidratos no intestino grosso, é esperado que ocorra um aumento no número de microorganismos nesta região e, consequentemente, um aumento do nitrogênio total nas fezes (CHANNON; ROWE; HERD, 2007). 


\section{MATERIAL E MÉTODOS}

\subsection{Animais e dieta}

Foram utilizados 64 bovinos machos inteiros da raça Black Angus com peso corporal médio inicial de $321 \mathrm{~kg}$ e idade média de 10 meses, provenientes de recria em sistema de pastejo contínuo e mantidos em confinamento no Centro de Referência Angus (CRA) na Fazenda Verdana, localizada no município de Itatinga/SP por um período de 56 dias precedidos de 56 dias de adaptação. Os animais foram separados em dois lotes iguais e tiveram seu peso e consumo avaliados diariamente em sistema integrado de obtenção de dados em tempo real (AF Master, Intergado, Brasil).

A dieta foi composta por ração desenvolvida pelo próprio CRA (Tabela 1), bagaço e silagem e foi fornecida ad libitum na forma de ração total misturada (RTM). A composição da dieta pode ser vista na Tabela 2. Esta teve proporção de $20 \%$ de concentrado e $80 \%$ de volumoso, com $11 \%$ de proteína bruta.

Tabela 1 - Composição da dieta

\begin{tabular}{lr}
\hline Ingrediente & $68 \%$ \\
\hline Silagem & $12 \%$ \\
Bagaço & $20 \%$ \\
Ração CRA (Tabela 2) & $38 \%$ \\
\hline Níveis da Ração & $11 \%$ \\
\hline Matéria seca & \\
Proteína bruta & \\
Energia metabolizável & $38 \%$ \\
Fibra em detergente neutro & $35 \%$ \\
\hline & $32 \%$ \\
Tabela 2 - Composição da ração CRA & $23 \%$ \\
\hline Ingrediente & $10 \%$ \\
\hline Milho moído & \\
Farelo de soja & $21 \%$ \\
Farelo de trigo & $67 \%$ \\
\hline Núcleo & \\
\hline Níveis da Ração & \\
\hline Proteína bruta & \\
Nutrientes digestíveis totais & \\
\hline
\end{tabular}




\subsection{Medidas de eficiência alimentar}

Os animais foram caracterizados quanto as variáveis: ganho de peso diário (GMD), ingestão média diária de matéria seca (IMS), peso vivo médio (PVM) e peso vivo médio metabólico (PMM). A eficiência foi estimada pelas variáveis: conversão alimentar (IMS/GMD) e consumo alimentar residual (CAR) proposto por Koch et al. (1963) calculado como a diferença entre a IMS observada e a IMS estimada. O PMM foi obtido pela equação do peso vivo médio elevado a $0,75\left(\mathrm{PVM}^{0,75}\right)$. O GMD no período foi determinado como coeficiente angular da regressão linear dos PV obtidos nas diferentes pesagens e respectivos dias experimentais.

\subsection{Avaliação de carcaça por ultrassonografia}

Os animais foram avaliados por ultrassonografia (US) na região do músculo Longissimus dorsi (contrafilé) para as medidas de área de olho de lombo (AOL) espessura de gordura na $12^{\mathrm{a}}$ e $13^{\mathrm{a}}$ costelas $(E G)$, espessura de gordura na garupa (EGP8), acabamento (ACAB) e porcentagem de gordura intramuscular (PGIM) nos manejos de pesagem, utilizando o equipamento Aloka SSD500.

\subsection{Coleta de amostras biológicas e extração de DNA}

Ao final do período de confinamento os animais foram levados ao tronco de contençã e amostras de fezes foram coletadas diretamente da ampola retal e mantidas em freezer $\left(-20^{\circ} \mathrm{C}\right)$ até sua utilização. Para extração de DNA total, utilizouse o kit para isolamento de DNA genômico bacteriano de amostra de fezes (QIAmp DNA Stool Mini, Qiagen, EUA) de acordo com as instruções do fabricante. A concentração e integridade das amostras de DNA foram avaliadas pela determinação da razão A260/280 em espectofotômetro (NanoDrop 2000, ThermoScientific, EUA) . Amostras que apresentaram valor da razão A260/280 inferior a 1,80 foram descartadas e extraídas novamente de acordo com os valores pré-estabelecidos pela empresa que realizou o sequenciamento. O DNA extraído foi mantido à temperatura de $-20^{\circ} \mathrm{C}$ até ser enviado para sequenciamento. 


\subsection{Preparo de Bibliotecas e Sequenciamento}

As amostras de DNA total foram devidamente encaminhadas à empresa NGS Soluções Genômicas, localizada no município de Piracicaba/SP, que realizou o preparo das bibliotecas genômicas e sequenciamento conforme descrito abaixo.

O preparo das bibliotecas foi realizado seguindo as recomendações Illumina (Figura 1). Os primers utilizados para amplificação locus-específica de bactérias flanqueia a região V3-V4 de 444 pb entre 341 e 785 pb com base no genoma de referência de Escherichia coli, já o primer de Arquéia de 457pb, está localizado entre 349 e 806 pb. Sequência overhang de adaptadores está incluída nos primers locus-específicos. As sequências de adaptadores Illumina, que foram hibridizadas com as sequências imobilizadas na lâmina de sequenciamento são:

"Forward overhang":

5' TCGTCGGCAGCGTCAGATGTGTATAAGAGACAG-[sequência locus-específica] "Reverse overhang":

5' GTCTCGTGGGCTCGGAGATGTGTATAAGAGACAG-[ sequência locusespecífica]

O sequenciamento foi realizado no sistema Miseq, conforme descrito na Figura 1, e as "reads" produzidos foram de 2x250 pb.

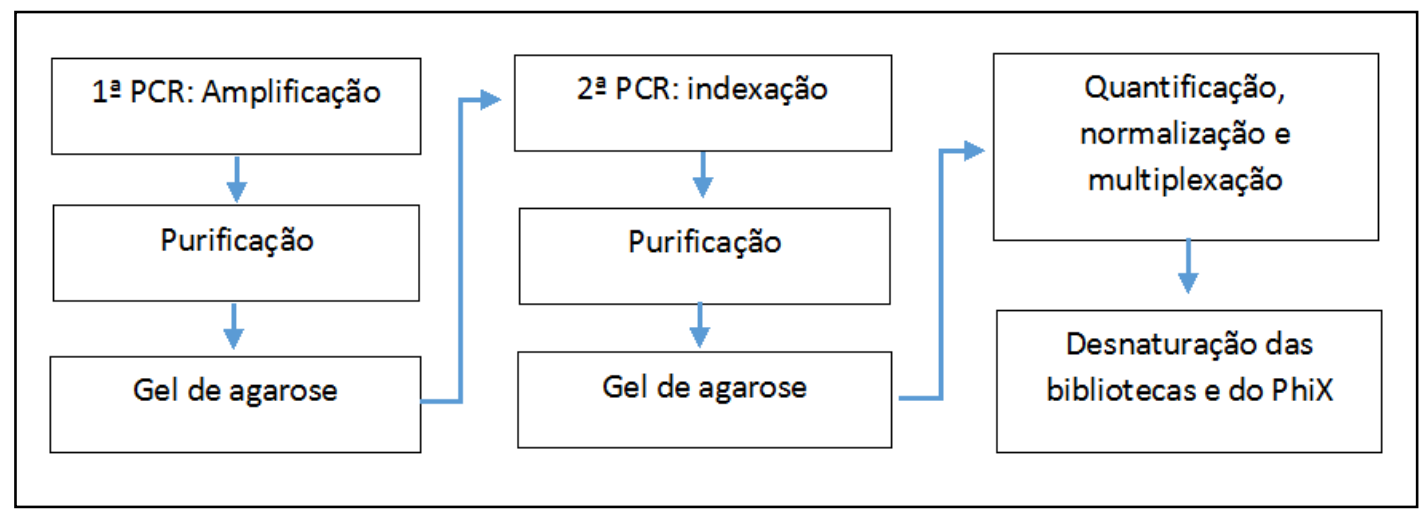

Figura 1. Protocolo padrão de preparo de bibliotecas para sequenciamento.

A primeira PCR é realizada para amplificação locus-específica. Após, AMPure $X P$ "beads" são utilizadas para purificação da reação de PCR. Então, o tamanho dos fragmentos gerados na reação de PCR é avaliado por eletroforese em gel de agarose. A segunda PCR é realizada para ligar os "barcodes" do kit Nextera XT, e outras etapas de purificação da PCR e validação das bibliotecas são realizadas. Posteriormente, as bibliotecas são quantificadas, para que todas as 
amostras/bibliotecas sejam unidas de maneira equimolar em um único pool. Para introduzir complexidade ao sequenciamento, um controle heterogêneo, o fago PhiX, foi combinado com o pool de "amplicons". Por fim, a desnaturação das bibliotecas e do PhiX é realizada para permitir o sequenciamento.

\subsection{Análise de dados}

Os dados foram analisados pela empresa NGS - Soluções Genômicas (Piracicaba/SP) conforme previamente publicado por Callahan et al. (2016). Primeiramente as "reads" multiplexadas foram atribuídas em amostras biológicas. programa DADA2, um pacote aberto implementado na linguagem $R$ (Callahan et al., 2015), foi utilizado para modelagem e correção de erros de "amplicons", sem a construção de unidades taxonômicas operacionais (OTUs). Estudos mostram que em várias comunidades simuladas, DADA2 identificou variantes mais reais e produziu menos sequências espúrias que outros métodos (Callahan et al., 2015). O pacote DADA2 tem um "pipeline" completo implementado para transformar os arquivos "fastq" do sequenciador em sequências de amostras inferidas, desmembradas, sem quimera. A filtragem de arquivos "fastq" foi realizada para cortar as sequências dos "primers", filtrar as extremidades devido ao decaimento da qualidade $(\mathrm{Q}<30)$. A filtragem removeu apenas $5 \mathrm{pb}$ de cada extremidade das "reads" "forward" e "reverse", mantendo a sobreposição para posterior junção das reads e remontar o fragmento completo sequenciado. O algoritmo DADA2 faz uso de um modelo de erro paramétrico e cada conjunto de dados de amplicon tem um conjunto diferente de taxas de erro. O método "learnErrors" aprende esse modelo de erros a partir dos dados, alternando a estimativa das taxas de erro e a inferência da composição da amostra até que eles convergem em uma solução consistente. Como em muitos problemas de aprendizado de máquina, o algoritmo deve começar com um palpite inicial, para o qual são usadas as taxas de erro máximas possíveis nesses dados (as taxas de erro se apenas a sequência mais abundante estiver correta e todo o restante for erros). Após a etapa de desreplicação “denoising' é realizada para se obter uma lista detalhada de sequências únicas e suas abundâncias e produzir pontuação de qualidade de posição do consenso para cada sequência única, tomando a média das qualidades posicionais das leituras de componentes. DADA2 não cria OTUs e diferencia as variáveis de sequência 
relacionadas. Diferentemente de outros, esse "pipeline" realiza a fusão de "pairedend" "reads" após a etapa "denoising". Isso ocorre porque o algoritmo de "denoising" do núcleo usa a relação empírica entre o índice de qualidade e as taxas de erro, atingindo maior precisão através do desmembramento antes da fusão, embora com algum custo computacional. Como a fusão ocorre após a etapa denoising, é necessária sobreposição exata, sem "mismatches", uma vez que se espera que quase todos os erros de substituição já tenham sido removidos. Em seguida, quimeras são removidas.

Após o processamento inicial dos dados, as taxonomias foram atribuídas a cada ASVs (Amplicon Sequencing Variants) utilizando uma implementação do programa DADA2 do método de classificador bayesiano ingênuo para essa finalidade. A função "assignTaxonomy" toma como entrada um conjunto de sequências (ASVs) a serem classificadas e um conjunto de treinamento de sequências de referência com taxonomia conhecida, e atribui taxonômicas com pelo menos a confiança de inicialização do "minBoot bootstrap". O banco de dados de referência GTDB: "Genome Taxonomy Database” (http://gtdb.ecogenomic.org/) foi utilizado como referência.

Posteriormente os dados gerados pelo programa DADA2 foram importados para o programa "Phyloseq", também implementado no R. O pacote "phyloseq" é uma ferramenta para importar, armazenar, analisar e exibir graficamente dados complexos de sequenciamento filogenético que já foram agrupados em ASVs. Este pacote aproveita muitas das ferramentas disponíveis em $\mathrm{R}$ para ecologia e análise filogenética (vegan, ade4, ape, picante), enquanto também usa sistemas gráficos avançados / flexíveis (ggplot2) para produzir facilmente gráficos com qualidade de publicação. As ASVs que não estavam presentes em pelo menos $20 \%$ das amostras foram removidas tanto para a análise dos dados de Arquéia, quanto para os dados de bactéria. As análises de diversidade Alpha e Beta foram realizadas no pacote "phyloseq", conforme descrito em: https://f1000research.com/articles/5-1492

Em seguida o arquivo "phyloseq" com as contagens das taxonomias foi importado para o programa "edgeR" (ROBINSON et al., 2010), um pacote do "R/Bioconductor" (GENTLEMAN et al., 2004). Para análise de abundância diferencial entre grupos e a análise dos dados contínuos, os pacotes "limma voom" foram utilizados para normalização, juntamente com o "edgeR". Estes abordam simultaneamente os problemas de (1) bibliotecas de sequenciamento de DNA de 
tamanhos amplamente diferentes e (2) proporções de contagem de ASVs que variam mais do que o esperado em um modelo de Poisson. Por isso, foram utilizadas implementações mais populares desta abordagem atualmente usada na análise de "RNA-Seq", nomeada de "edgeR", adaptadas para dados de microbiomas. Essa abordagem permite uma comparação válida entre as ASVs, melhorando substancialmente tanto a potência quanto a precisão na detecção da abundância diferencial. De acordo com o "EdgeR User Guide", o modelo linear (ImFit) foi ajustado para idade para testar o efeito da abundância relativa de cada Bactéria e Arquéia no consumo alimentar residual. 


\section{RESULTADOS}

\subsection{Caracterização fenotípica dos animais}

Primeiramente foi realizada a análise de estatística descritiva básica para todos os 64 animais dos fenótipos observados durante o experimento. Foram calculados, média, desvio-padrão, mínimo e máximo do peso inicial, peso final, ganho de peso, ingestão de matéria seca e medidas de eficiência alimentar. Os valores estão descritos na tabela 3 .

Tabela 3. Médias, desvios padrão, valores mínimos e valores máximos das medidas de PVI, PVF, IMS, GMD, CA e CAR coletadas em confinamento $(n=64)$.

\begin{tabular}{lccc}
\hline & Média & Mínimo & Máximo \\
\hline PVI(kg) & $321 \pm 60,14$ & 194 & 433 \\
PVF(kg) & $420 \pm 61,71$ & 288 & 529 \\
IMS(kg/dia) & $9,23 \pm 1,10$ & 7,20 & 12,00 \\
GMD(kg/dia) & $1,74 \pm 0,32$ & 0,685 & 2,377 \\
CA & $5,45 \pm 1,02$ & 4,299 & 10,558 \\
CAR(kg/dia) & $0 \pm 0,50$ & $-1,132$ & 1,181 \\
\hline
\end{tabular}

Na tabela 4 são demonstrados os valores de correlação entre ganho de peso, consumo e características de EA. Foi possível observar correlação moderada e negativa entre CA e GMD $(-0,69)$. Não foi observada correlação entre CAR E GMD, no entanto, o CAR apresentou correlação baixa e positiva com IMS $(0,43)$. 
Tabela 4. Correlação entre as características de PVI, PVF, IMS, GMD, CA e CAR ( $n=64)$.

\begin{tabular}{lcccccc}
\hline & $\mathrm{PVI}$ & $\mathrm{PVF}$ & $\mathrm{IMS}$ & $\mathrm{GMD}$ & $\mathrm{CA}$ & $\mathrm{CAR}$ \\
\hline $\mathrm{PVI}^{\circ}$ & - & $0,94^{*}$ & $0,59^{*}$ & $-0,07$ & $0,61^{*}$ & 0,007 \\
$\mathrm{PVF}^{*}$ & & - & $0,77^{*}$ & 0,23 & $0,36^{*}$ & $-0,006$ \\
$\mathrm{IMS}^{*}$ & & - & $0,61^{*}$ & 0,06 & $0.430^{*}$ \\
$\mathrm{GMD}^{*}$ & & & - & $-0,69^{*}$ & 0,050 \\
$\mathrm{CA}^{\circ}$ & & & & - & $0.340^{*}$ \\
$\mathrm{CAR}^{\circ}$ & & & & & - \\
\hline
\end{tabular}

${ }^{*} p<0,05$

'Correlação de Pearson (dados paramétricos)

${ }^{\circ}$ Correlação de Spearman (dados não-paramétricos)

Foram avaliadas as correlações entre peso inicial, final, médio e metabólico; ingestão de matéria seca, ganho de peso e medidas de EA com medidas de ultrassonografia de carcaça (Tabela 5). Observa-se que existe correlação alta e positiva entre PVF e AOL $(0,72)$, correlação moderada e positiva entre as medidas de peso e as medidas de ultrassonografia de carcaça $(0,49$ a 0,68$)$, com exceção da porcentagem de gordura intramuscular, que não apresentou correlação significativa com nenhuma das características avaliadas. A medida de ingestão de matéria seca apresentou correlação moderada e positiva com AOL $(0,50)$ e EG $(0,34)$. As medidas de ganho de peso e consumo alimentar residual não apresentaram valores de correlação significativos com as medidas de ultrassonografia. No entanto, nota-se correlação baixa e positiva da CA com EG $(0,31)$, EGP8 $(0,36)$ e ACAB $(0,40)$. 
Tabela 5 - Correlações entre PVI, PVF, PVM PMM, IMS, GMD, CA e CAR com medidas de ultrassonografia de carcaça $(n=64)$.

\begin{tabular}{lllllllll}
\hline & $\mathrm{PVI}^{\circ}$ & $\mathrm{PVF}^{\star}$ & $\mathrm{PVM}^{\circ}$ & $\mathrm{PMM}^{\circ}$ & $\mathrm{IMS}^{\star}$ & $\mathrm{GMD}^{\star}$ & $\mathrm{CA}^{\circ}$ & $\mathrm{CAR}^{\circ}$ \\
\hline $\mathrm{AOL}^{\star}$ & $0.64^{*}$ & $0.72^{*}$ & $0.68^{*}$ & $0.68^{*}$ & $0.50^{*}$ & $0.25^{*}$ & 0,09 & $-0,19$ \\
$\mathrm{EG}^{\star}$ & $0.59^{*}$ & $0.56^{*}$ & $0.59^{*}$ & $0.59^{*}$ & $0.34^{*}$ & 0,05 & $0.31^{*}$ & $-0,13$ \\
$\mathrm{EGP8}^{\star}$ & $0.53^{*}$ & $0.49^{*}$ & $0.52^{*}$ & $0.52^{*}$ & 0,24 & $-0,13$ & $0.36^{*}$ & $-0,07$ \\
$\mathrm{ACAB}^{\star}$ & $0,59^{*}$ & $0.55^{*}$ & $0.57^{*}$ & $0.58^{*}$ & $0.29^{*}$ & $-0,09$ & $0.40^{*}$ & $-0,08$ \\
$\mathrm{PGIM}^{\circ}$ & $-0,24$ & $-0,23$ & $-0,24$ & $-0,24$ & $-0,11$ & 0,1 & $-0,16$ & 0,06 \\
\hline
\end{tabular}

${ }^{*} \mathrm{p}<0,05$

'Correlação de Pearson (dados paramétricos)

${ }^{\circ}$ Correlação de Spearman (dados não-paramétrico)

\subsection{Caracterização dos grupos de alta e baixa eficiência alimentar}

A partir da criação dos grupos de alta e baixa (AEA e BEA) eficiência alimentar pelo CAR, realizou-se a análise da estatística descritiva dos mesmos e os testes de comparação de média entre os grupos para todas as características. Como pode ser visto na Tabela 6, não houve diferença significativa para as medidas de peso entre os grupos, bem como ganho de peso (GMD). No entanto, verificou-se diferença significativa $(p<0,05)$ na ingestão de matéria seca (IMS), sendo maior nos animais de BEA, bem como na conversão alimentar (CA) e no consumo alimentar residual (CAR). 
Tabela 6. Médias, desvios padrão, valores mínimos e valores máximos dos grupos de eficiência alimentar (BEA, $n=15)$ e (AEA, $n=15$ ) para as medidas PVI, PVF, PVM, PMM, (IMS), (GMD), CA, CAR , AOL, EG, EGP8, ACAB, E PGIM; e valor de significância da diferença entre as médias dos grupos.

\begin{tabular}{|c|c|c|c|c|c|c|c|}
\hline & $\begin{array}{c}\text { Mínimo } \\
\text { BEA }\end{array}$ & $\begin{array}{c}\text { Mínimo } \\
\text { AEA }\end{array}$ & $\begin{array}{c}\text { Máximo } \\
\text { BEA }\end{array}$ & $\begin{array}{c}\text { Máximo } \\
\text { AEA }\end{array}$ & $\begin{array}{l}\text { Média } \\
\text { BEA }\end{array}$ & $\begin{array}{l}\text { Média } \\
\text { AEA }\end{array}$ & pValor \\
\hline $\mathrm{PVI}(\mathrm{kg})^{\circ}$ & 216 & 219 & 416 & 413 & $334 \pm 68,10$ & $322 \pm 66,12$ & 0,5658 \\
\hline $\operatorname{PVF}(\mathrm{kg})^{\star}$ & 314 & 313 & 529 & 508 & $430 \pm 71,29$ & $421 \pm 65,69$ & 0,7101 \\
\hline $\operatorname{PVM}(\mathrm{kg})^{\circ}$ & 265 & 266 & 473 & 456 & $382 \pm 68,98$ & $372 \pm 65,64$ & 0,6224 \\
\hline $\mathrm{PMM}(\mathrm{kg})^{\circ}$ & 66 & 66 & 101 & 99 & $86 \pm 11,81$ & $84 \pm 11,30$ & 0,6224 \\
\hline IMS(kg/dia) ${ }^{\bullet}$ & 7,23 & 7,19 & 12,02 & 10,07 & $9,96 \pm 1,24$ & $8,61 \pm 0,84$ & $0,0017^{*}$ \\
\hline GMD $(k g / d i a)^{\star}$ & 0,685 & 1,227 & 2,080 & 2,238 & $1,678 \pm 0,35$ & $1,724 \pm 0,27$ & 0,6878 \\
\hline $\mathrm{CA}^{\circ}$ & 4,721 & 4,299 & 10,558 & 6,903 & $6,177 \pm 1,39$ & $5,075 \pm 0,72$ & $0,0095^{*}$ \\
\hline $\operatorname{CAR}(\mathrm{kg} / \mathrm{dia})^{\circ}$ & 0,359 & $-1,132$ & 1,181 & $-0,355$ & $0,702 \pm 0,21$ & $-0,606 \pm 0,23$ & $<.0001^{*}$ \\
\hline $\mathrm{AOL}\left(\mathrm{cm}^{2}\right)^{\bullet}$ & 50,34 & 51,15 & 96,04 & 93,06 & $69,19 \pm 11,43$ & $73,68 \pm 12,61$ & 0,3150 \\
\hline $\mathrm{EG}(\mathrm{mm})^{\star}$ & 2,79 & 2,79 & 6,35 & 7,44 & $4,60 \pm 1,10$ & $4,86 \pm 1,36$ & 0,5693 \\
\hline $\operatorname{EGP} 8(\mathrm{~mm})^{\star}$ & 2,70 & 1,80 & 8,10 & 8,56 & $5,42 \pm 1,71$ & $5,31 \pm 1,95$ & 0,8768 \\
\hline $\mathrm{ACAB}(\mathrm{mm})^{\star}$ & 3,02 & 2,15 & 7,37 & 7,71 & $5,13 \pm 1,37$ & $5,15 \pm 1,68$ & 0,9698 \\
\hline PGIM(\%) & 2,20 & 2,45 & 5,29 & 5,39 & $3,35 \pm 1,06$ & $3,61 \pm 0,94$ & 0,3103 \\
\hline
\end{tabular}




\subsection{Caracterização dos dados de sequenciamento}

\subsubsection{SEQUENCIAMENTO 16S DE BACTÉRIAS}

Foram determinados 21 filos taxonômicos com grande variação de abundância relativa entre estes como pode ser visto na tabela 7. Os filos mais prevalentes foram Bacteroidetes, Firmicutes, Verrucomicrobia e Proteobacteria.

Tabela 7. Caracterização taxonômica de bactérias

\begin{tabular}{lccc}
\hline Filo & Número de "features" por filo & Prevalência média & Abundância total \\
\hline Firmicutes & 11297 & 1,717890 & 2377338 \\
Bacteroidetes & 5016 & 1,871810 & 1336667 \\
Proteobacteria & 753 & 1,717131 & 363485 \\
Verrucomicrobia & 777 & 1,585586 & 197185 \\
Spirochaetes & 250 & 1,800000 & 83283 \\
Actinobacteria & 228 & 1,631579 & 59571 \\
Euryarchaeota & 117 & 2,478632 & 57841 \\
Candidatus_Saccharibacteria & 169 & 1,538462 & 26376 \\
Tenericutes & 380 & 1,410526 & 22867 \\
Lentisphaerae & 232 & 1,560345 & 19916 \\
Planctomycetes & 91 & 1,351648 & 9106 \\
Elusimicrobia & 92 & 1,130435 & 6946 \\
Synergistetes & 19 & 1,263158 & 575 \\
Fibrobacteres & 4 & 1,000000 & 219 \\
Fusobacteria & 8 & 1,125000 & 99 \\
\hline Acidobacteria & 7 & 1,000000 & 91 \\
Chloroflexi & 7 & 1,285714 & 85 \\
Cyanobacteria/Chloroplast & 2 & 1,000000 & 24 \\
Thaumarchaeota & 2 & 1,000000 & 21 \\
Chlamydiae & 1 & 1,000000 & 12 \\
Parcubacteria & 261 & 1,000000 & 6 \\
NA & & & - \\
\hline
\end{tabular}

Para as análises posteriores foi realizada a filtragem para exclusão de filos por baixa prevalência/abundância, onde os filos "Chlamydiae", "Chloroflexi", "Cyanobacteria/Chloroplast", "Thaumarchaeota" e "Parcubacteria" foram excluídos. $\mathrm{Na}$ figura 2 é possível verificar a prevalência dos 16 filos remanescentes. 


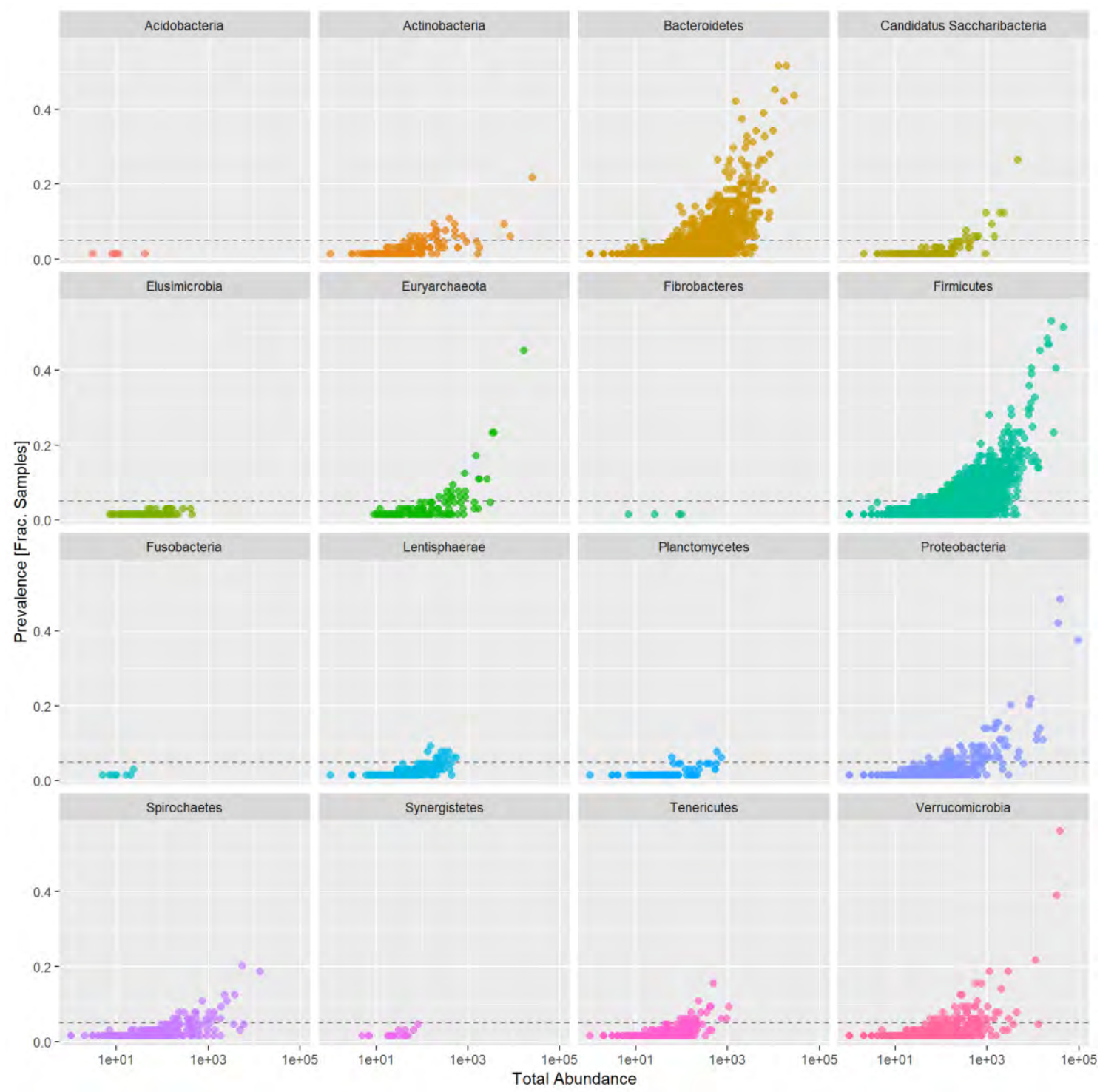

Figura 2. Filos remanescentes após filtro de baixa prevalência/abundância.

Foram removidos os micro-organismos determinados em menos de $5 \%$ das amostras e posteriormente os resultados com mesma espécie ou sub-espécie foram aglomerados em nível de espécie como pode ser visto na figura 3 que compara a árvore filogenética antes e após esta etapa. Isto resultou em 138 espécies taxonômicas para análises posteriores. 


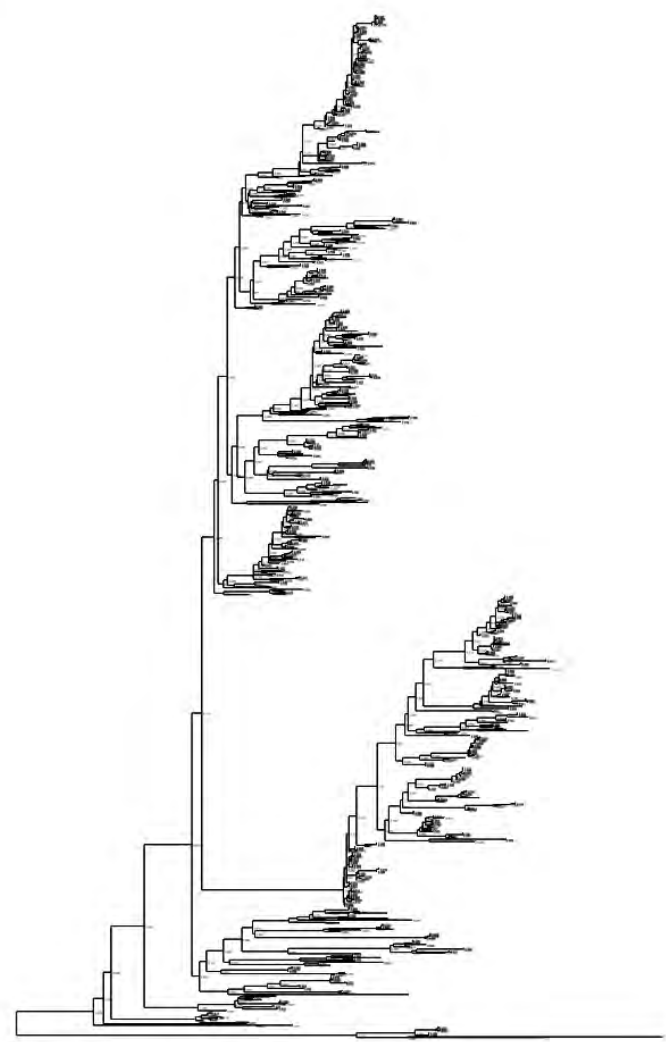

By Species

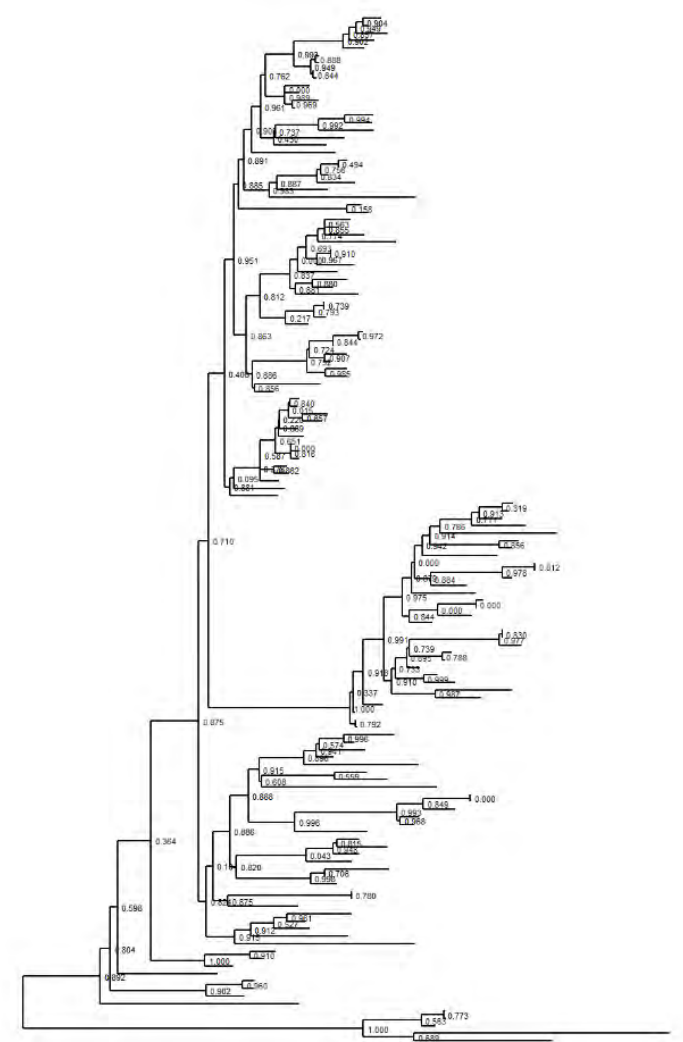

Figura 3. Árvores filogenéticas em nível de espécie antes e após a aglomeração por similaridade.

Os dados foram analisados quanto à diversidade Beta utilizando o "weighted Unifrac" para evidenciar efeitos da idade, CAR e filos taxonômicos pela análise de coordenadas principais (PCoA). Não foi possível evidenciar agrupamentos específicos das amostras por esta análise para idade e CAR como pode ser visto nas figuras 4 e 5 . Já a análise de PCoA para os diferentes filos demonstrou que estes se agrupam por similaridade genética conforme esperado (Figuras 6 e7). 


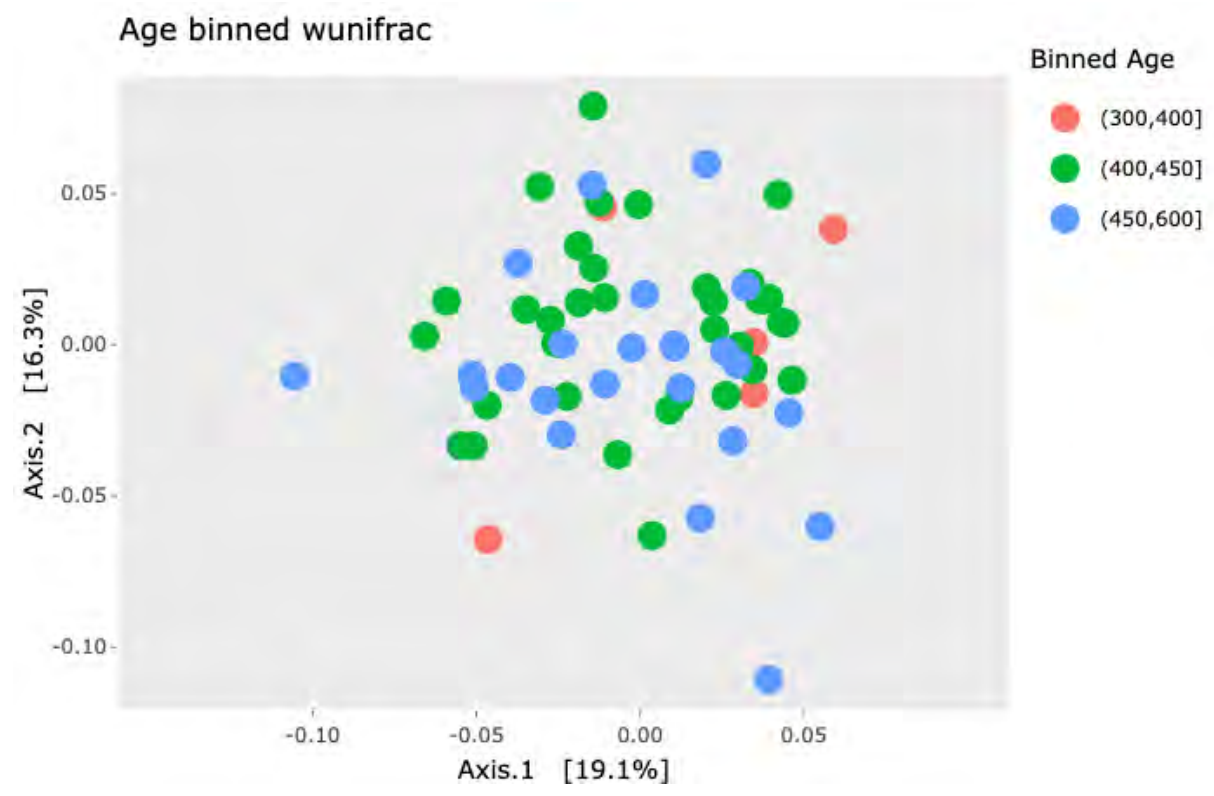

Figura 4. Análise de Coordenadas Principais ( $\mathrm{PCoA})$ para idade dos animais. São mostrados 3 grupos de animais clusterizados pela idade em dias. Não é possível evidenciar efeito da idade sobre a composição das populações bacterianas.

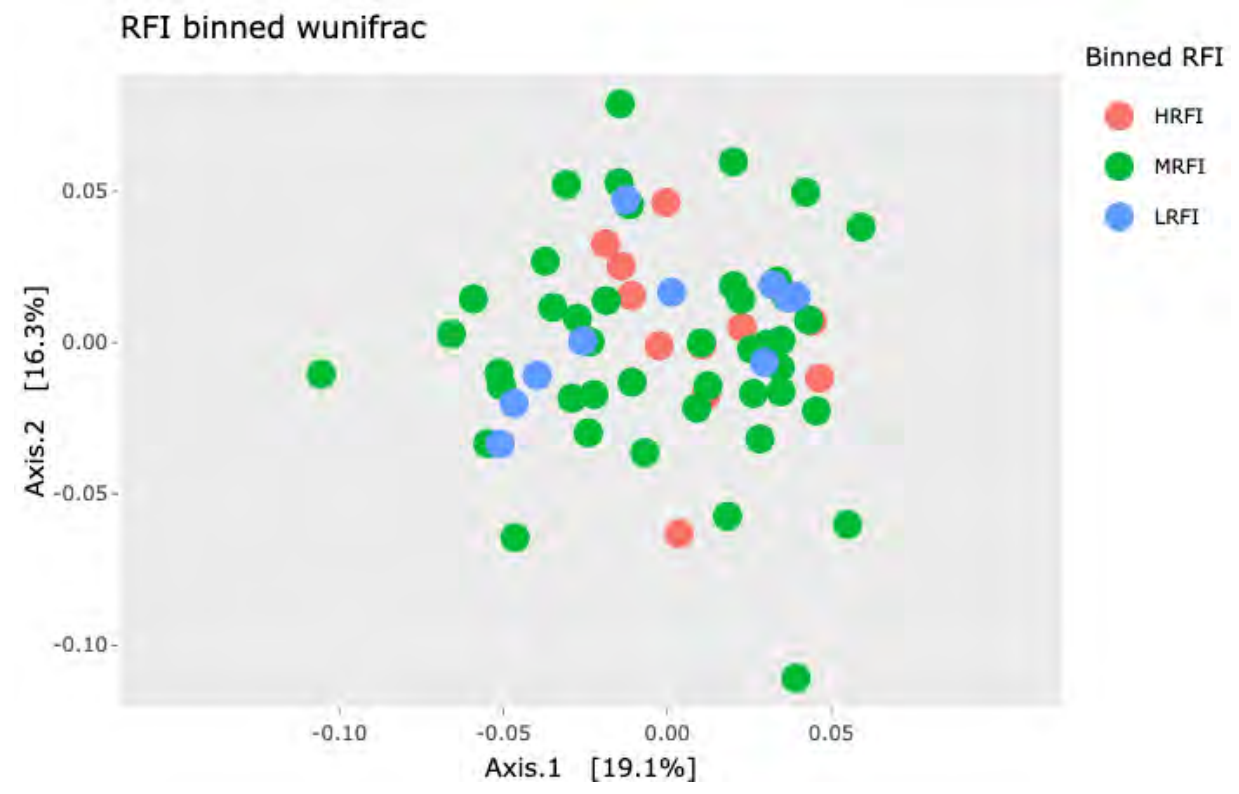

Figura 5. Análise de Coordenadas Principais (PCoA) para CAR (RFI) dos animais. São mostrados 3 grupos de animais clusterizados pelo CAR. Não é possível evidenciar efeito do CAR sobre a composição das populações bacterianas. 


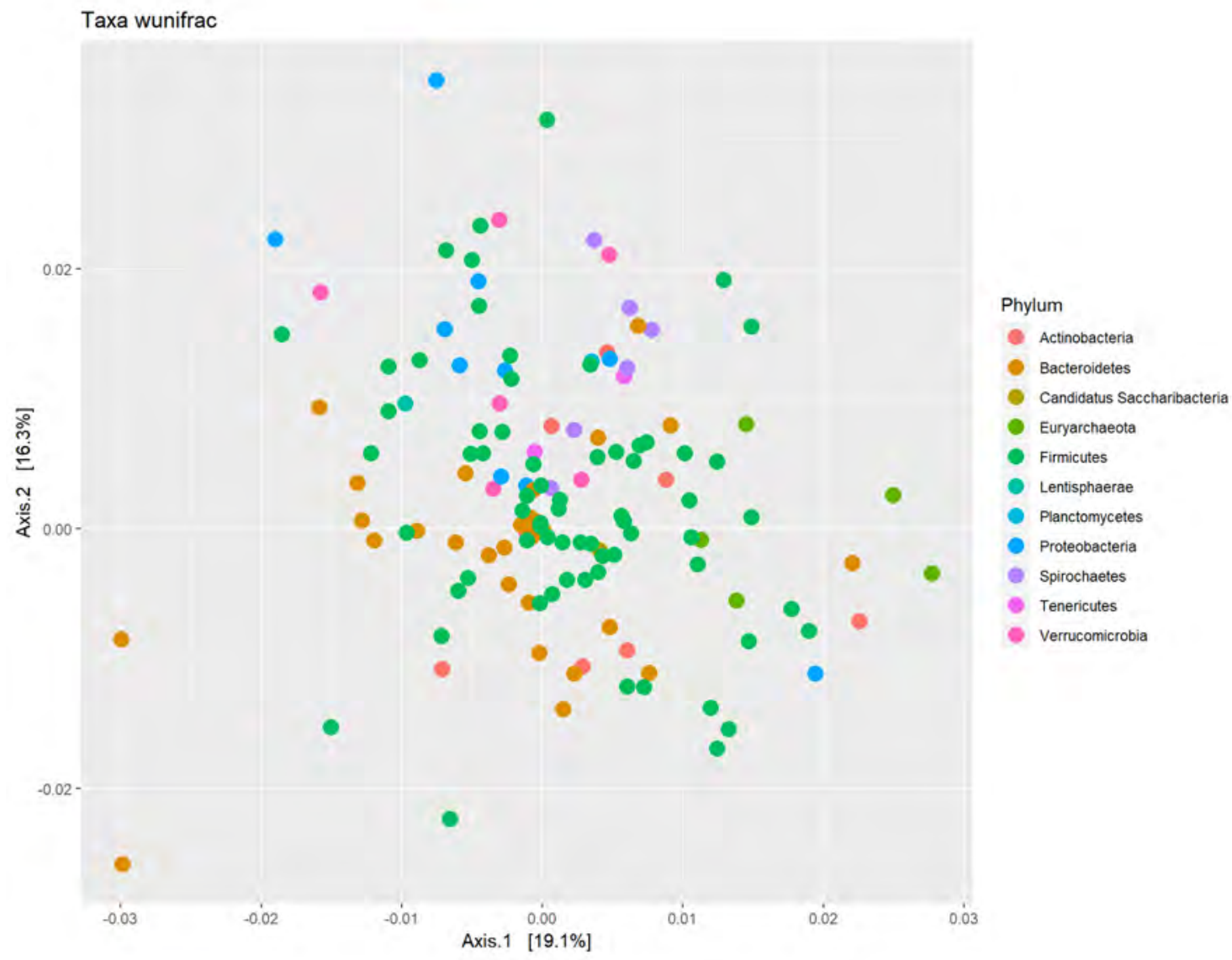

Figura 6. Análise de Coordenadas Principais (PCoA) para os principais filos encontrados. É possível notar certa aglomeração de amostras de mesmo filo pelo PCoA. 


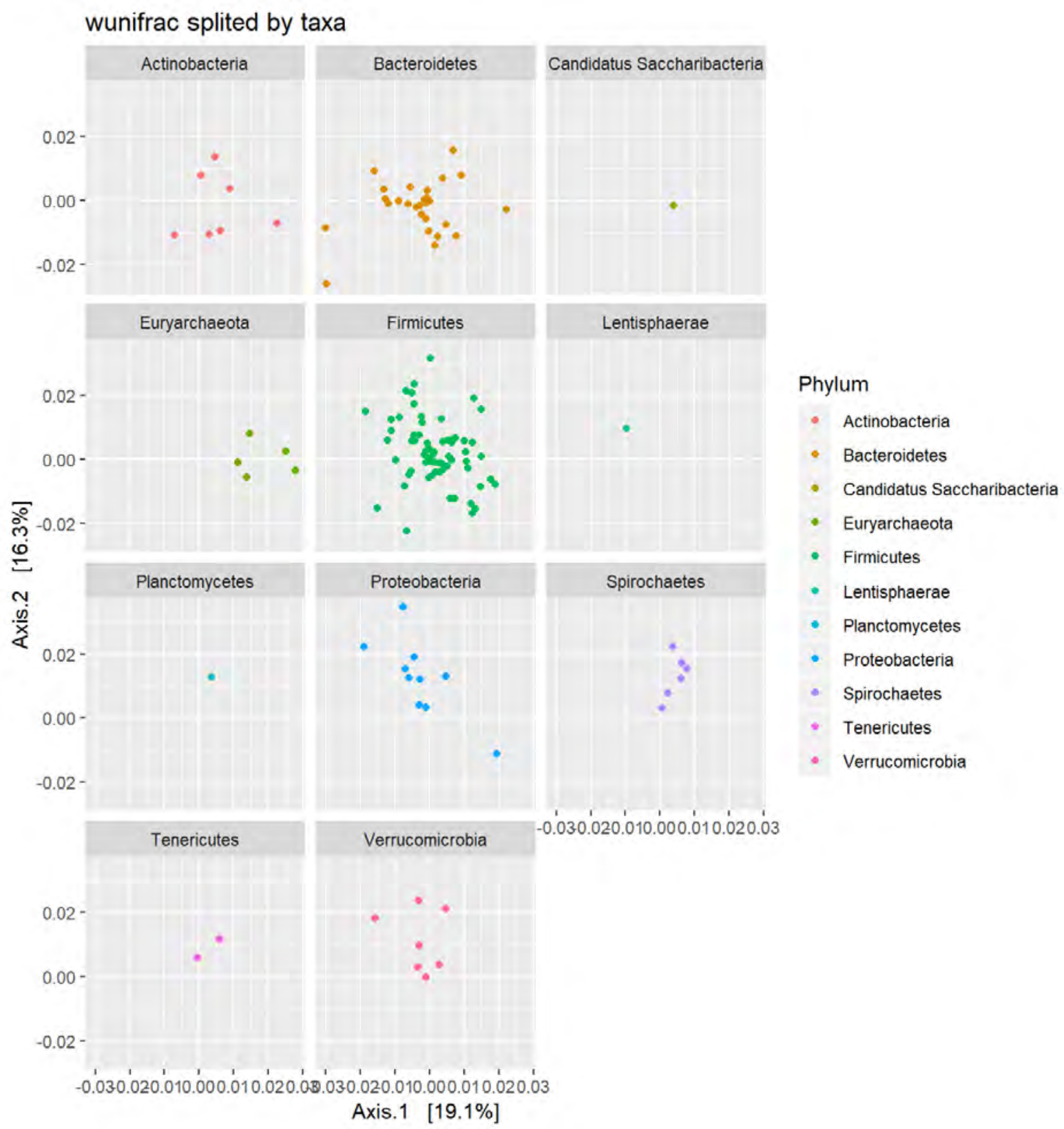

Figura 7. Análise de Coordenadas Principais (PCoA) para os principais filos encontrados. É possível notar certa aglomeração de amostras de mesmo filo pelo PCoA.

A diversidade alfa foi analisada pelo índice de Shannon que demonstra 0 quão diferente é a abundância dos micro-organismos nas amostras. A visualização dos índices de diversidade foi realizada para verificar uma eventual influência do CAR, idade e lote de animais na diversidade. No entanto, não foi observado nenhum efeito. (Figuras 8, 9 e 10). 


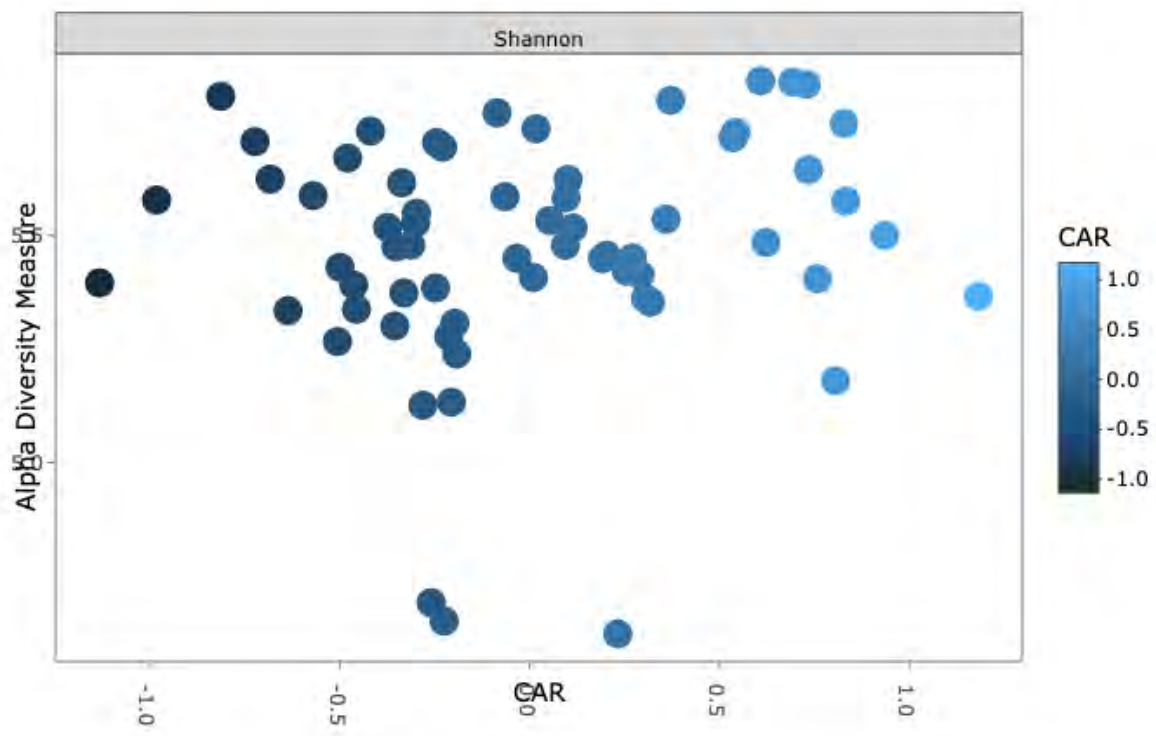

Figura 8. Análise de Diversidade alfa (Shannon) e CAR. Nenhuma correlação foi evidenciada entre estes parâmetros.

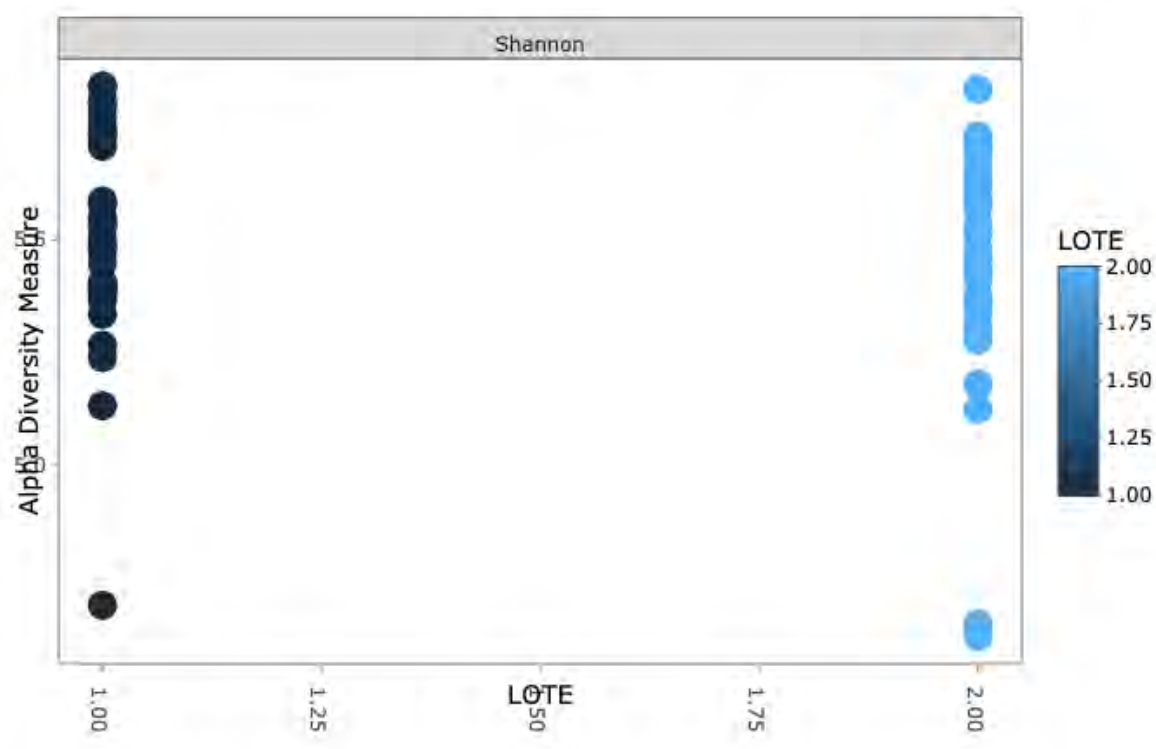

Figura 9. Análise de Diversidade Alfa (Shannon) e lote. Nenhuma correlação foi evidenciada entre estes parâmetros. 


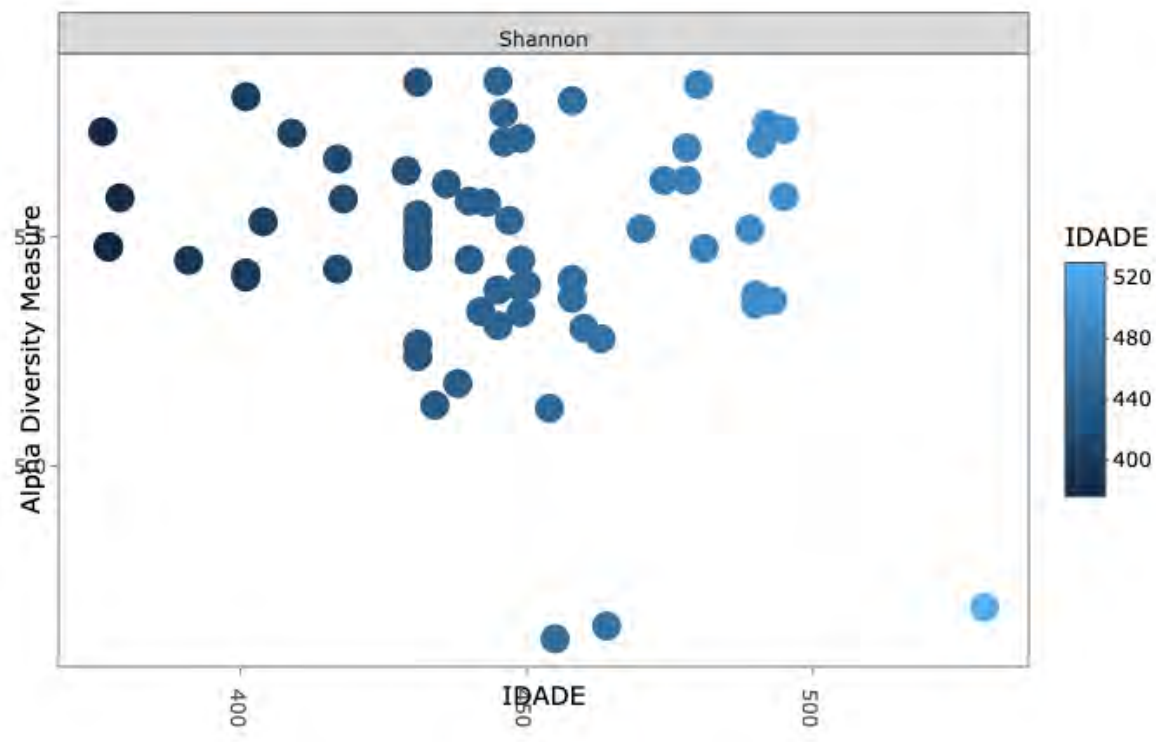

Figura 10. Análise de Diversidade alfa (Shannon) e idade. Nenhuma correlação foi evidenciada entre estes parâmetros.

Nas figuras 11, 12, 13, 14, 15, 16 e 17 são apresentadas as abundâncias relativas por reino, filo, classe, ordem, família, gênero e espécie nas amostras experimentais onde pode ser notado variação populacional nas amostras experimentais. 


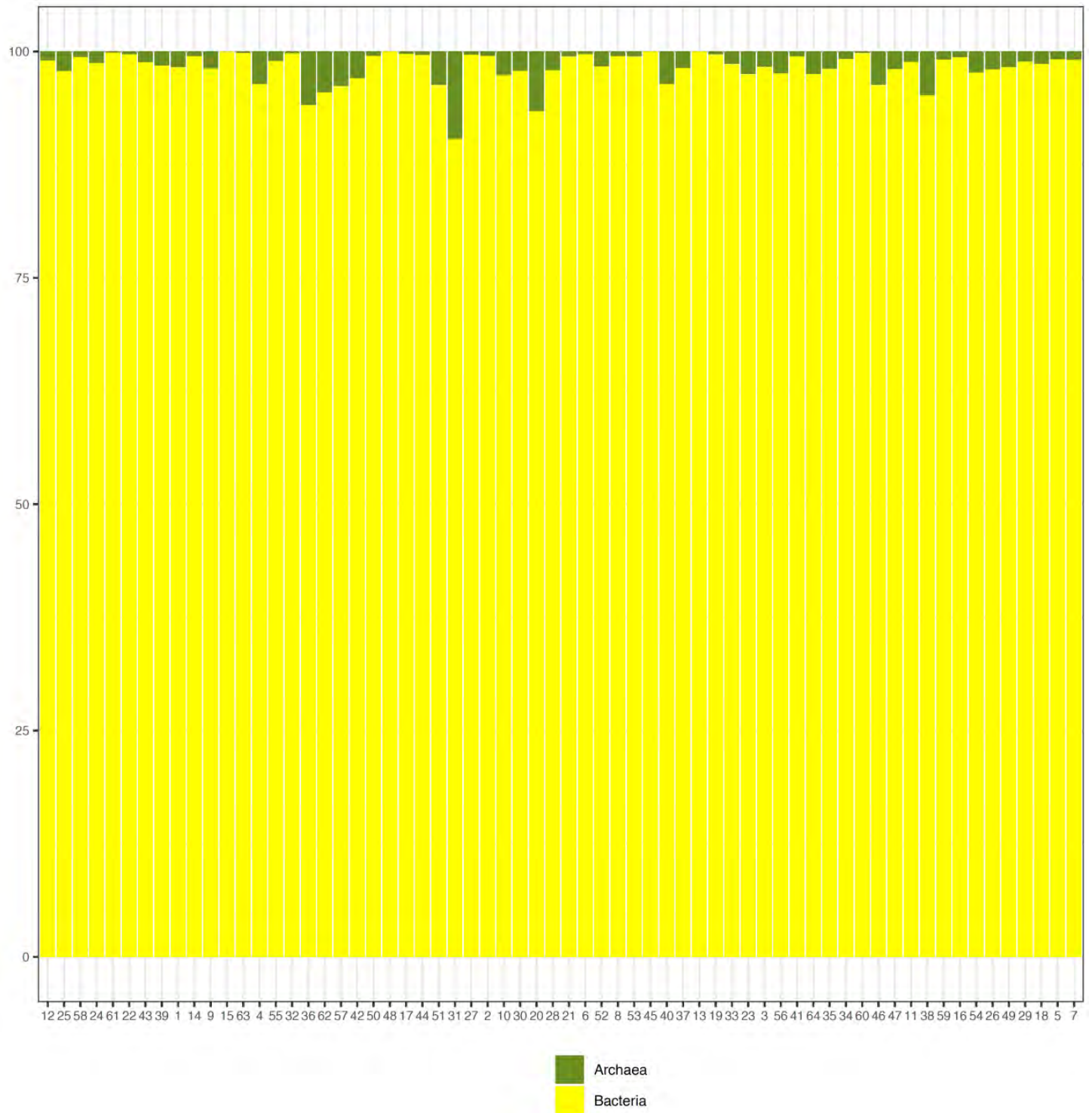

Figura 11. Abundância relativa dos reinos nas amostras experimentais. Amostras classificadas do maior CAR para o menor CAR. 

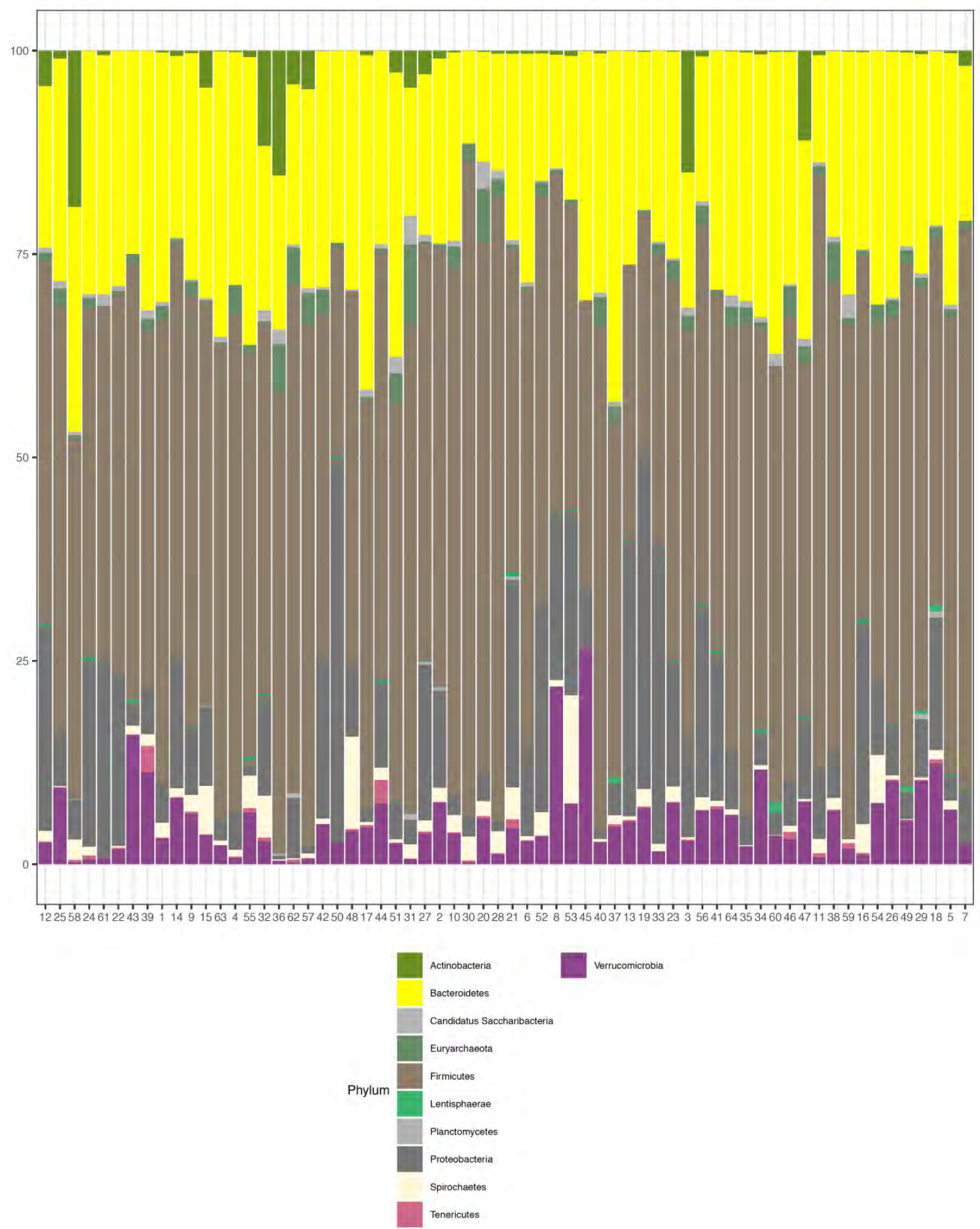

Figura 12. Abundância relativa dos filos nas amostras experimentais. Amostras classificadas do maior CAR para o menor CAR. 

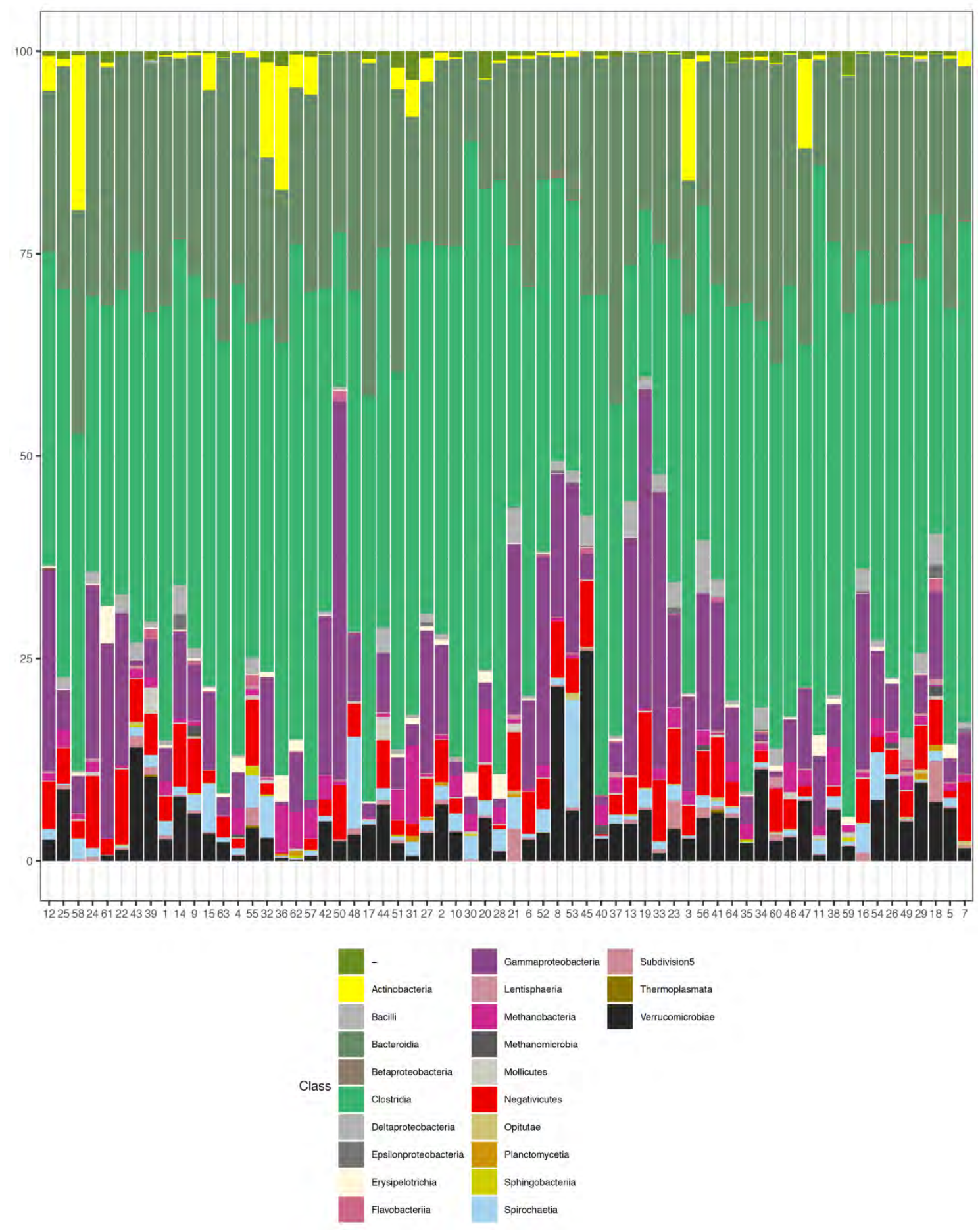

Figura 13. Abundância relativa das classes nas amostras experimentais. Amostras classificadas do maior CAR para o menor CAR. 

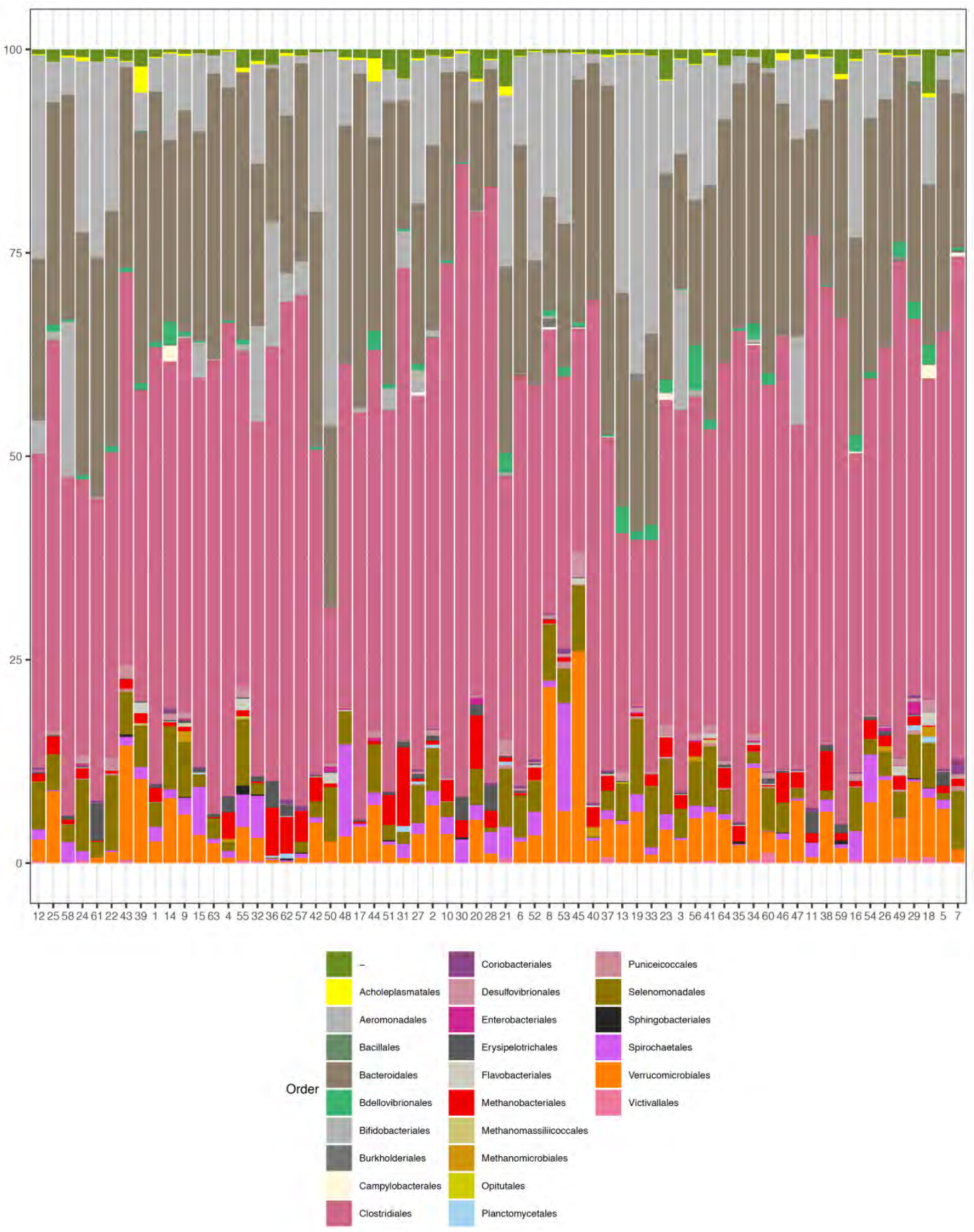

Figura 14. Abundância relativa das ordens nas amostras experimentais. Amostras classificadas do maior CAR para o menor CAR. 

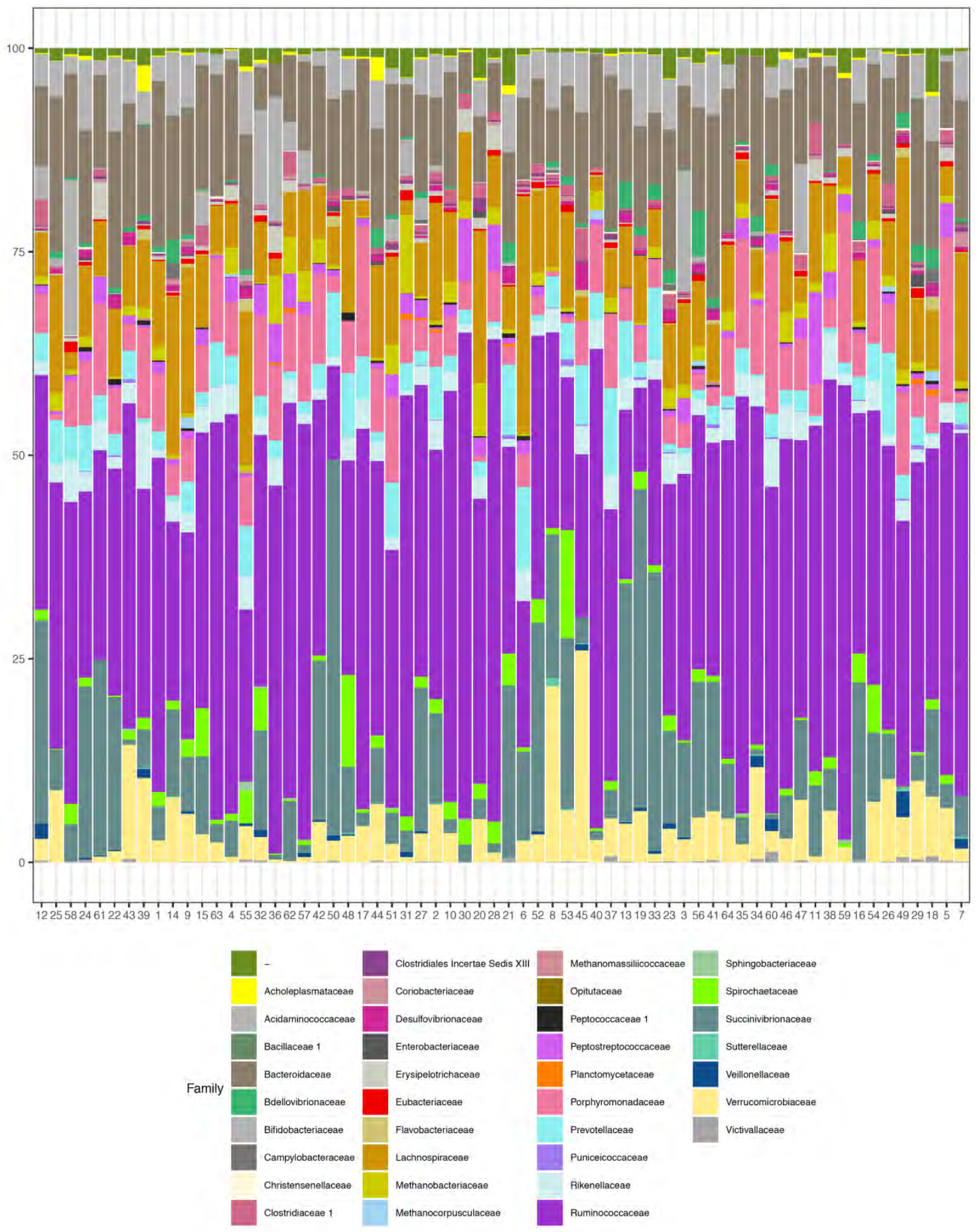

Figura 15. Abundância relativa das famílias nas amostras experimentais. Amostras classificadas do maior CAR para o menor CAR. 

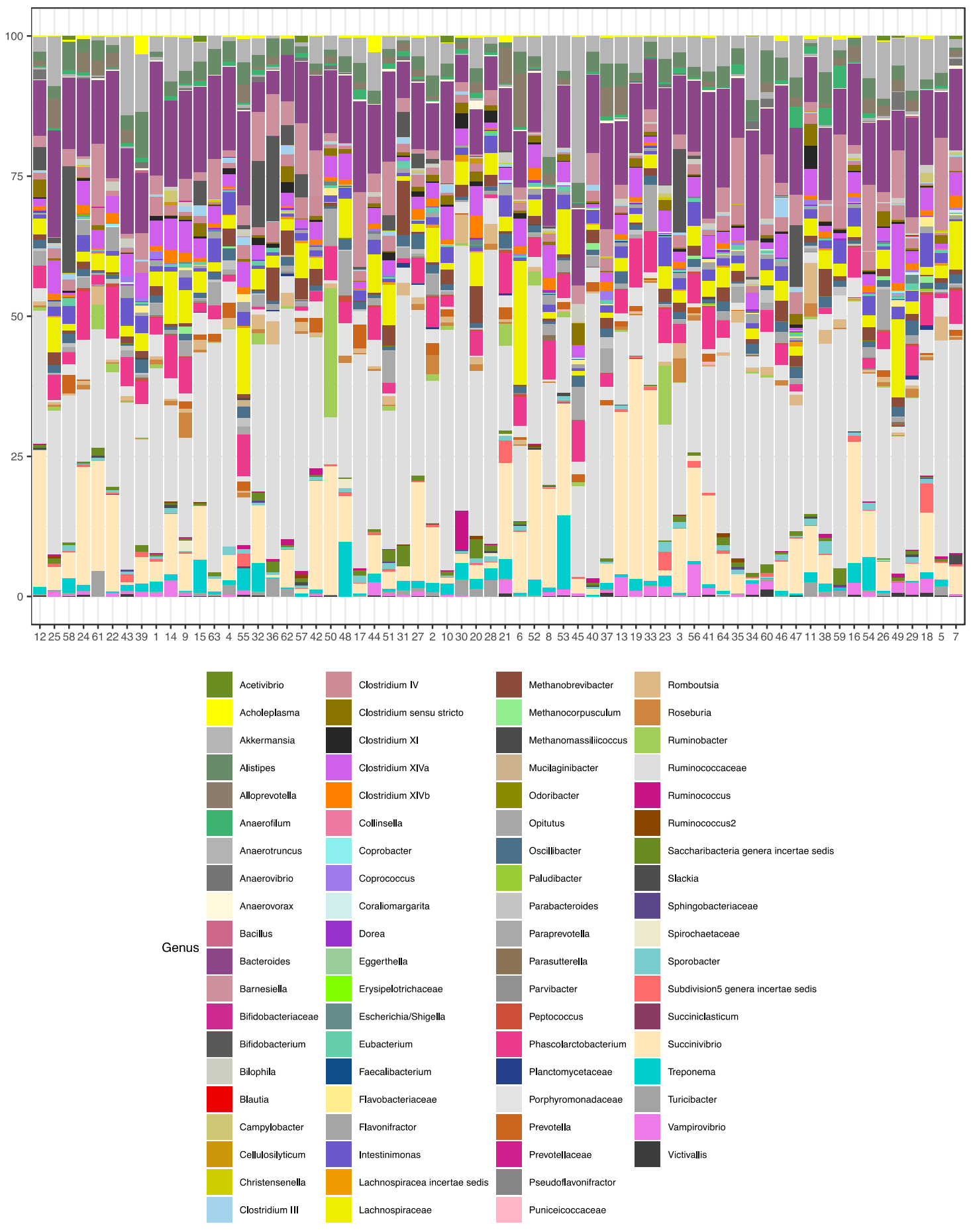

Figura 16. Abundância relativa dos gêneros nas amostras experimentais. Amostras classificadas do maior CAR para o menor CAR. 

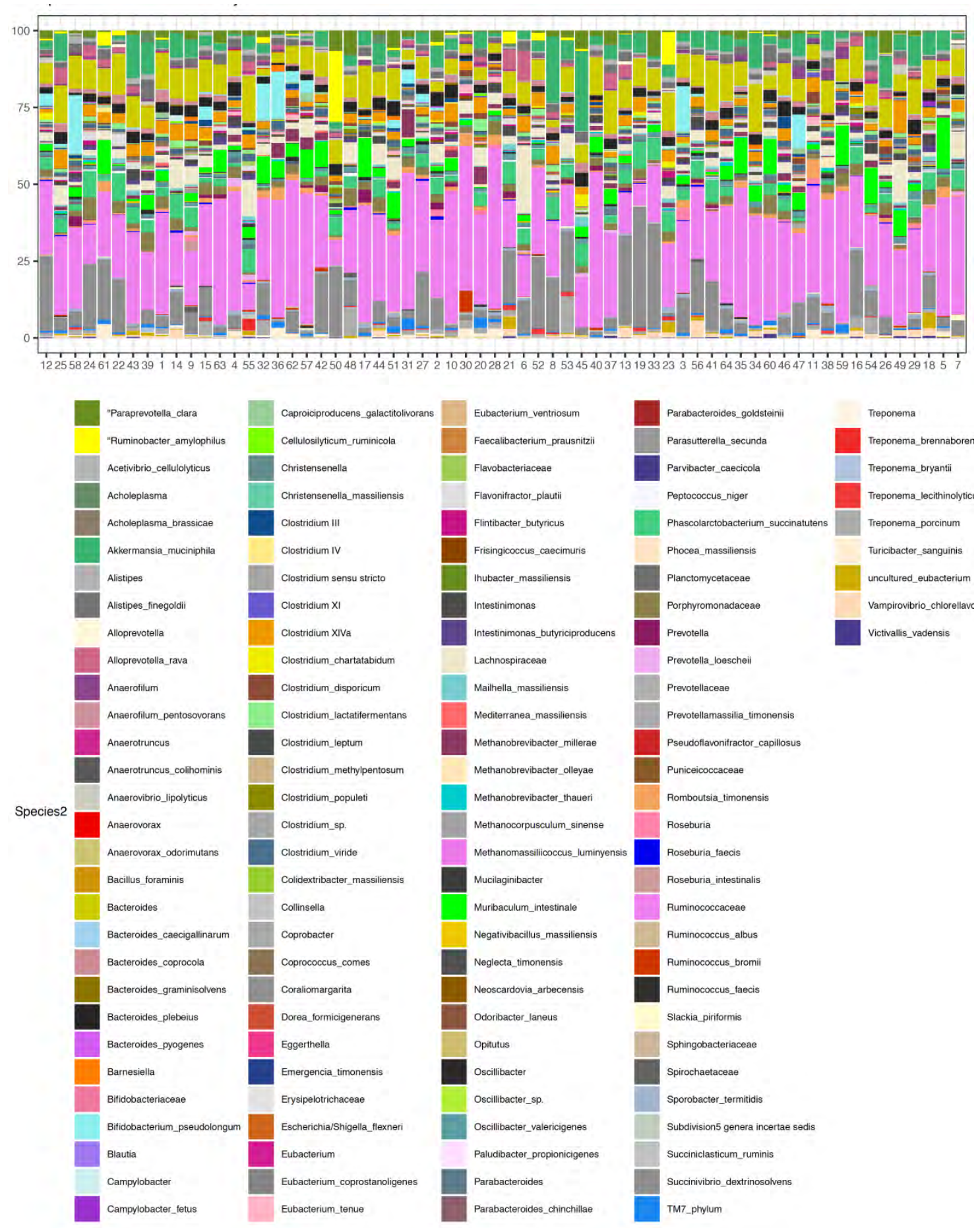

Figura 17. Abundância relativa das espécies nas amostras experimentais. Amostras classificadas do maior CAR para o menor CAR. 
Por fim a abundância relativa específica associada ao CAR e a CA foi analisada de duas maneiras: uma considerando todas as amostras $(n=64)$ no modelo estatístico considerando-se também o pai, a idade e o lote dos animais e uma segunda análise comparativa entre os grupos de alto e baixo CAR e alta e baixa CA.

$\mathrm{Na}$ primeira análise foi possível identificar 9 micro-organismos associados significativamente ao CAR considerando-se $p<0,05$ (Tabela 9) e 5 micro-organismos associados significativamente a CA (Tabela 11). Quando a análise foi feita por grupos, observou-se 8 micro-organismos com diferença significativa para os grupos de alto e baixo CAR e apenas 1 diferentemente abundante entre os grupos de alto e baixo CA (Tabelas 10 e 12).

Quando analisados micro-organismos que apresentaram diferença significativa em ambas as análises com relação ao CAR, apenas o micro-organismo Eubacterium sp. foi negativamente associado e com relação ao CA apenas o microorganismo Bacteroides $s p$. apresentou diferença significativa. 
Tabela 9. Micro-organismos significativamente associados ao CAR.

\begin{tabular}{|c|c|c|c|c|c|c|c|c|}
\hline Filo & Classe & Ordem & Família & Gênero & Espécie & $\log \mathrm{FC}$ & $\begin{array}{c}\text { Valor de } \\
\text { P }\end{array}$ & $\begin{array}{c}\text { Valor de } \\
\quad \mathrm{P} \text { aj }\end{array}$ \\
\hline Actinobacteria & Actinobacteria & Coriobacteriales & Coriobacteriaceae & Slackia & Slackia_piriformis(AB490806) & $-1,8865$ & 0,0022 & 0,1834 \\
\hline Firmicutes & Clostridia & Clostridiales & Clostridiaceae 1 & Clostridium sensu stricto & NA & $-1,6813$ & 0,00286 & 0,1834 \\
\hline Actinobacteria & Actinobacteria & Bifidobacteriales & Bifidobacteriaceae & Bifidobacterium & Bifidobacterium_pseudolongum(D86194) & 2,1263 & 0,0050 & 0,2191 \\
\hline Tenericutes & Mollicutes & Acholeplasmatales & Acholeplasmataceae & Acholeplasma & NA & 1,9679 & 0,0168 & 0,5514 \\
\hline Firmicutes & Clostridia & Clostridiales & Ruminococcaceae & Clostridium IV & Clostridium_methylpentosum(Y18181) & $-0,5867$ & 0,0371 & 0,6381 \\
\hline Verrucomicrobia & Subdivision5 & - & - & Subdivision5 genera incertae sedis & NA & $-1,0678$ & 0,0373 & 0,6381 \\
\hline Firmicutes & Clostridia & Clostridiales & Eubacteriaceae & Eubacterium & NA & $-0,7178$ & 0,0386 & 0,6381 \\
\hline Bacteroidetes & Bacteroidia & Bacteroidales & Rikenellaceae & Alistipes & NA & 1,1554 & 0,0390 & 0,6381 \\
\hline Bacteroidetes & Bacteroidia & Bacteroidales & Prevotellaceae & Prevotella & NA & 2,0586 & 0,0503 & 0,7326 \\
\hline
\end{tabular}

Tabela 10. Micro-organismos significativamente diferentes entre os grupos de alto e baixo CAR.

\begin{tabular}{|c|c|c|c|c|c|c|c|c|}
\hline Filo & Classe & Ordem & Família & Gênero & Espécie & $\log F C$ & Valor de P & Valor de $\mathrm{P}$ aj \\
\hline Firmicutes & Clostridia & Clostridiales & Christensenellaceae & Christensenella & NA & $-2,3353$ & $2,01 \mathrm{E}-05$ & 0,0028 \\
\hline Firmicutes & Clostridia & Clostridiales & Eubacteriaceae & Eubacterium & NA & $-1,9551$ & 0,0010 & 0,0695 \\
\hline Firmicutes & Clostridia & Clostridiales & Ruminococcaceae & Clostridium IV & NA & $-2,5847$ & 0,0033 & 0,1496 \\
\hline Firmicutes & Clostridia & Clostridiales & Clostridiaceae 1 & Clostridium sensu stricto & Clostridium_disporicum(Y18176) & $-3,6778$ & 0,0053 & 0,1834 \\
\hline Actinobacteria & Actinobacteria & Coriobacteriales & Coriobacteriaceae & Eggerthella & NA & $-0,9620$ & 0,0113 & 0,3105 \\
\hline Firmicutes & Clostridia & Clostridiales & Lachnospiraceae & Roseburia & Roseburia_faecis(AY305310) & 2,6229 & 0,0376 & 0,7804 \\
\hline Bacteroidetes & Bacteroidia & Bacteroidales & Porphyromonadaceae & NA & NA & 1,2654 & 0,0426 & 0,7804 \\
\hline Firmicutes & Clostridia & Clostridiales & Clostridiaceae 1 & Clostridium sensu stricto & Clostridium_chartatabidum (X71850) & 1,7804 & 0,0465 & 0,7804 \\
\hline
\end{tabular}


Tabela 11. Micro-organismos significativamente associados a CA.

\begin{tabular}{|c|c|c|c|c|c|c|c|c|}
\hline Filo & Classe & Ordem & Família & Gênero & Espécie & $\log \mathrm{FC}$ & $\begin{array}{c}\text { Valor de } \\
\text { P }\end{array}$ & $\begin{array}{c}\text { Valor de P } \\
\text { aj }\end{array}$ \\
\hline Bacteroidetes & Bacteroidia & Bacteroidales & Bacteroidaceae & Bacteroides & NA & $-2,0485$ & 0,0008 & 0,0493 \\
\hline Firmicutes & Clostridia & Clostridiales & Peptostreptococcaceae & Romboutsia & Romboutsia_timonensis(NR_144740.1) & $-1,9719$ & 0,0060 & 0,1885 \\
\hline Bacteroidetes & Bacteroidia & Bacteroidales & Rikenellaceae & Alistipes & Alistipes_finegoldii(AY643083) & 1,5610 & 0,0191 & 0,3443 \\
\hline Firmicutes & Negativicutes & Selenomonadales & Acidaminococcaceae & Phascolarctobacterium & Phascolarctobacterium_succinatutens(AB490811) & 1,9675 & 0,0219 & 0,3443 \\
\hline Bacteroidetes & Bacteroidia & Bacteroidales & Bacteroidaceae & Bacteroides & Bacteroides_plebeius(AB200217) & $-1,5666$ & 0,0284 & 0,3579 \\
\hline
\end{tabular}

Tabela 12. Micro-organismo significativamente diferente entre os grupos de alta e baixa CA.

\begin{tabular}{|c|c|c|c|c|c|c|c|c|}
\hline Filo & Classe & Ordem & Família & Gênero & Espécie & $\log \mathrm{FC}$ & Valor de P & Valor de $\mathrm{P}$ aj \\
\hline Bacteroidetes & Bacteroidia & Bacteroidales & Bacteroidaceae & Bacteroides & NA & $-2,7514$ & 0,0110 & 0,8205 \\
\hline
\end{tabular}




\subsubsection{SEQUENCIAMENTO 16S DE ARQUÉIAS}

Nesta análise foram determinados inicialmente 98 componentes do domínio Arquéia, 2639 do domínio Bacteria e outros 46 não determinados (NA). A filtragem dos não caracterizados reduziu de 2783 componentes para 1158 sendo estes utilizados para as análises subsequentes, assim tendo sido detectados 19 filos (Tabela 13). Como o foco foi análise de Arqueas, foram mantidos para as análises posteriores apenas os filos Euryarcheota e Thaumarchaeota (Figura 18), tendo sido utilizado filtro de baixa prevalência/abundância.

Tabela 13. Caracterização taxonômica dos filos encontrados

\begin{tabular}{lcc}
\hline Filo & Prevalência média & Abundância total \\
\hline Euryarchaeota & 10.078 .652 & 454311 \\
Verrucomicrobia & 6.032 .967 & 385300 \\
Lentisphaerae & 5.500 .000 & 93848 \\
Firmicutes & 2.193 .467 & 22908 \\
Bacteroidetes & 3.402 .597 & 13698 \\
Proteobacteria & 3.805 .556 & 6203 \\
Actinobacteria & 2.285 .714 & 1202 \\
Spirochaetes & 2.565 .217 & 1155 \\
Tenericutes & 2.300 .000 & 615 \\
Thaumarchaeota & 1.111 .111 & 216 \\
\hline Acidobacteria & 1.000 .000 & 105 \\
Planctomycetes & 1.000 .000 & 73 \\
Chlamydiae & 1.000 .000 & 48 \\
Elusimicrobia & 1.250 .000 & 29 \\
Candidatus Saccharibacteria & 1.000 .000 & 20 \\
Fibrobacteres & 1.000 .000 & 10 \\
Parcubacteria & 1.000 .000 & 9 \\
Armatimonadetes & 1.000 .000 & 5 \\
candidate division WPS-2 & 1.000 .000 & 4 \\
\hline
\end{tabular}




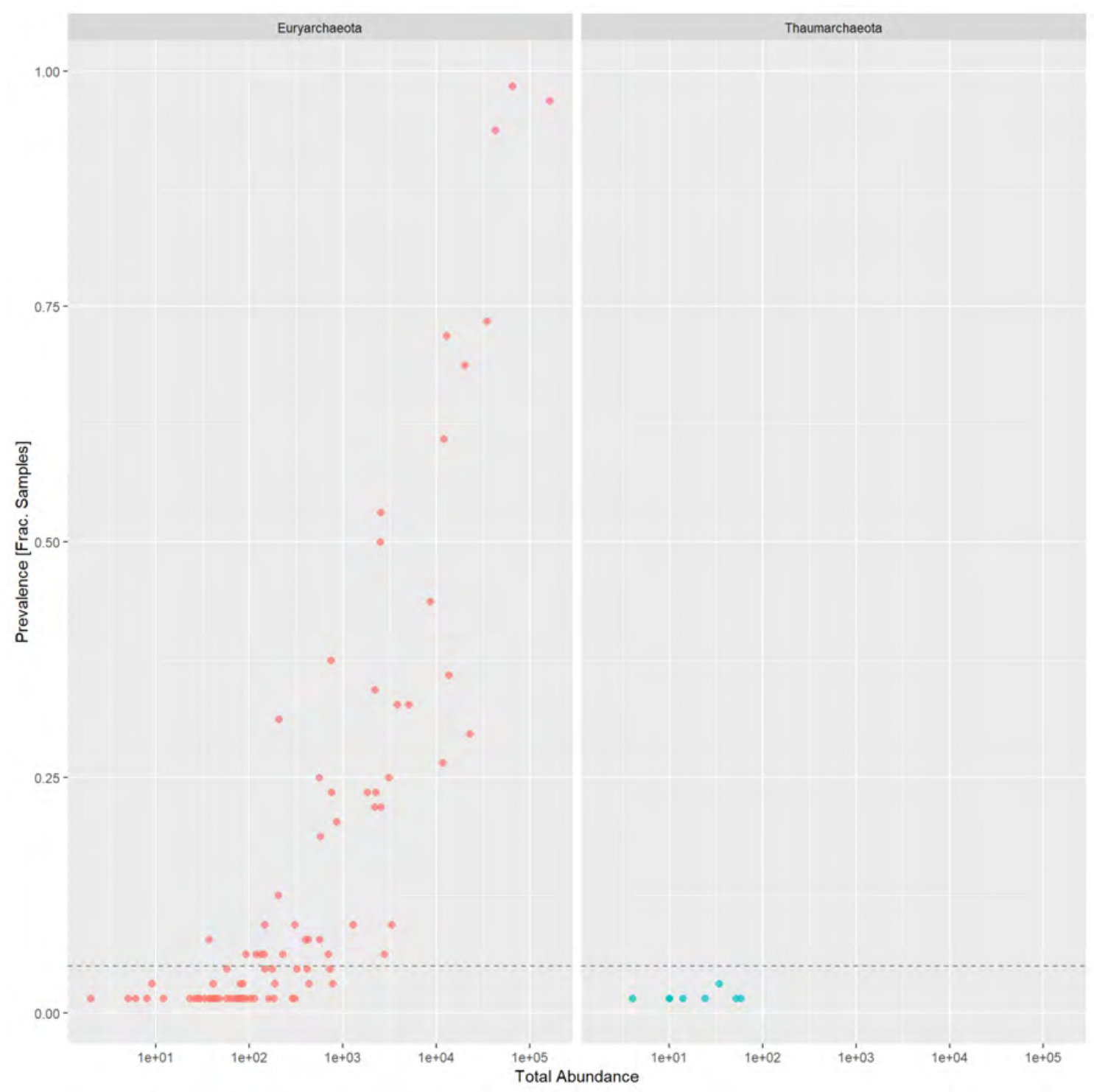

Figura 18. Filos remanescentes após filtro de baixa prevalência/abundância.

Foram removidos os micro-organismos determinados em menos de $5 \%$ das amostras e posteriormente os resultados com mesma espécie ou sub-espécie foram aglomerados em nível de espécie como pode ser visto na figura 19 que compara a árvore filogenética antes e após esta etapa. Isto resultou em 11 espécies taxonômicas para análises posteriores. 
Before Agglomeration

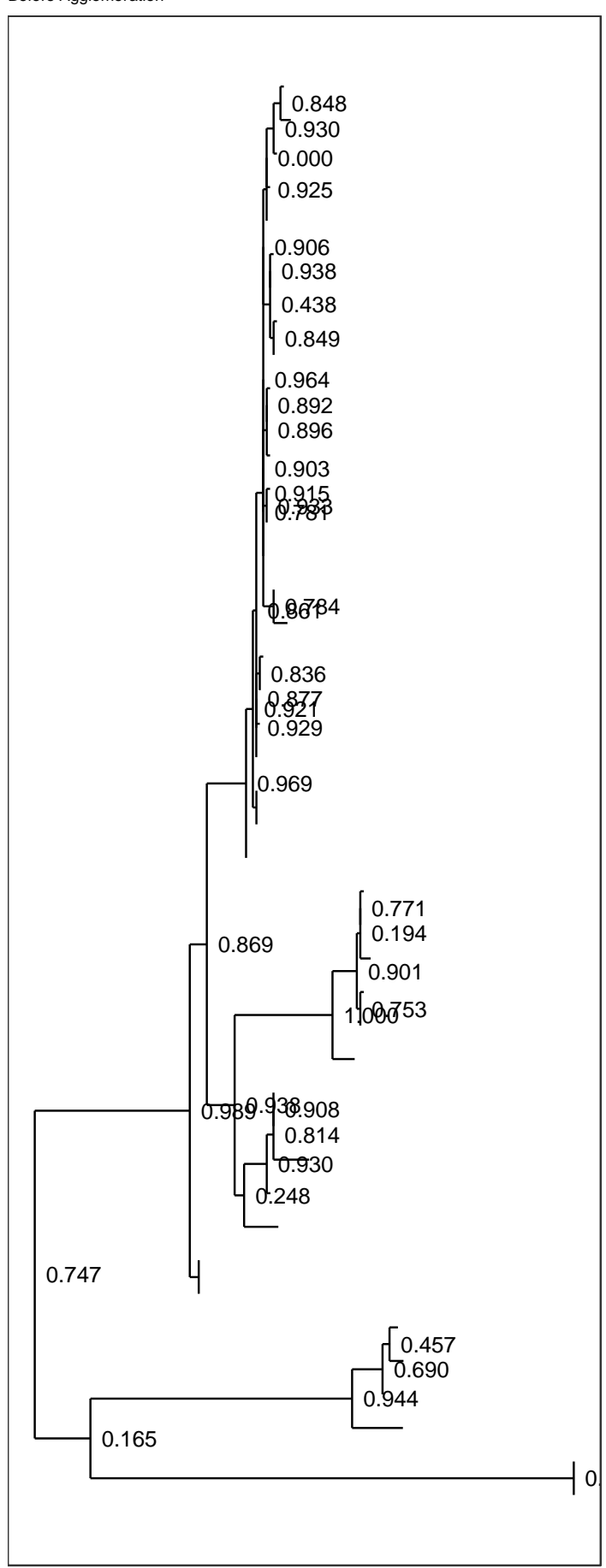

By Specie

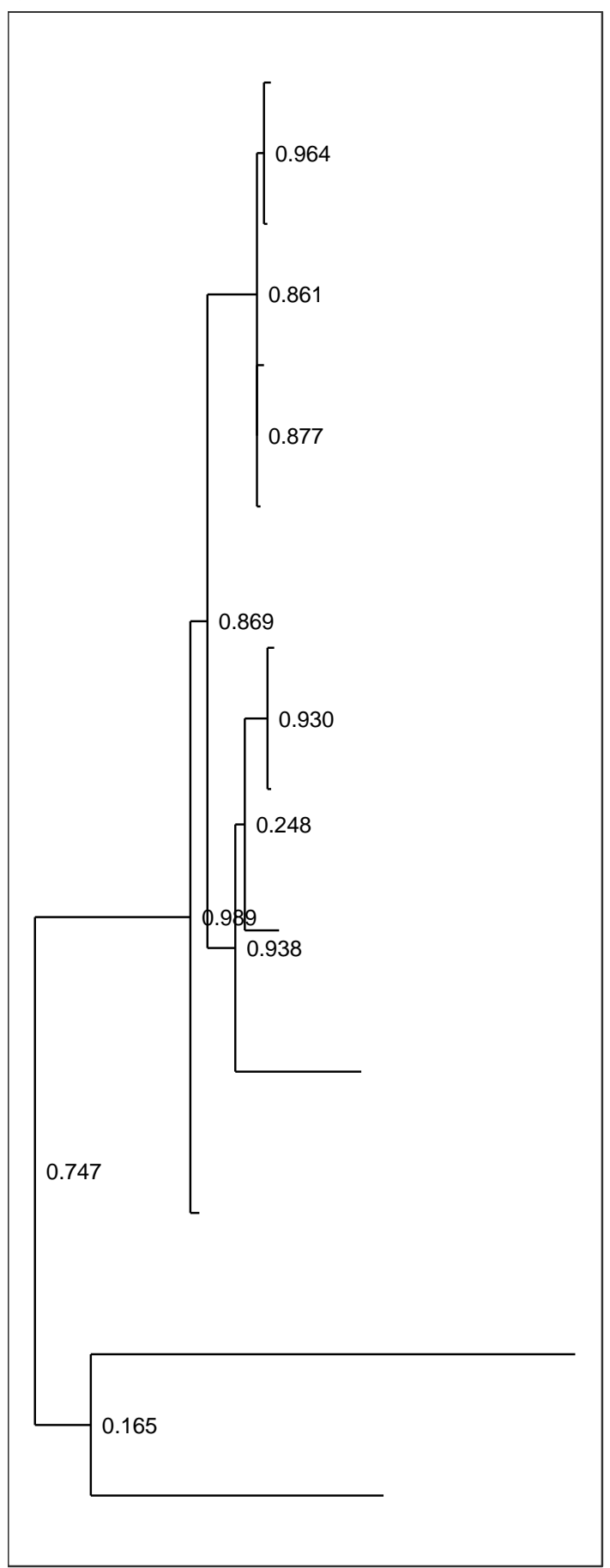

Figura 19. Árvores filogenéticas em nível de espécie antes e após a aglomeração por similaridade.

Os dados foram analisados quanto a diversidade Beta utilizando o "weighted Unifrac" para evidenciar efeitos da idade, CAR e filos taxonômicos pela análise de coordenadas principais (PCoA). Não foi possível evidenciar agrupamentos específicos das amostras por esta análise para idade e CAR como pode ser visto nas figuras 20 e 21 . 
Já a análise de PCoA para os diferentes gêneros demonstrou que estes se agrupam por similaridade genética conforme esperado (Figuras 22 e 23).

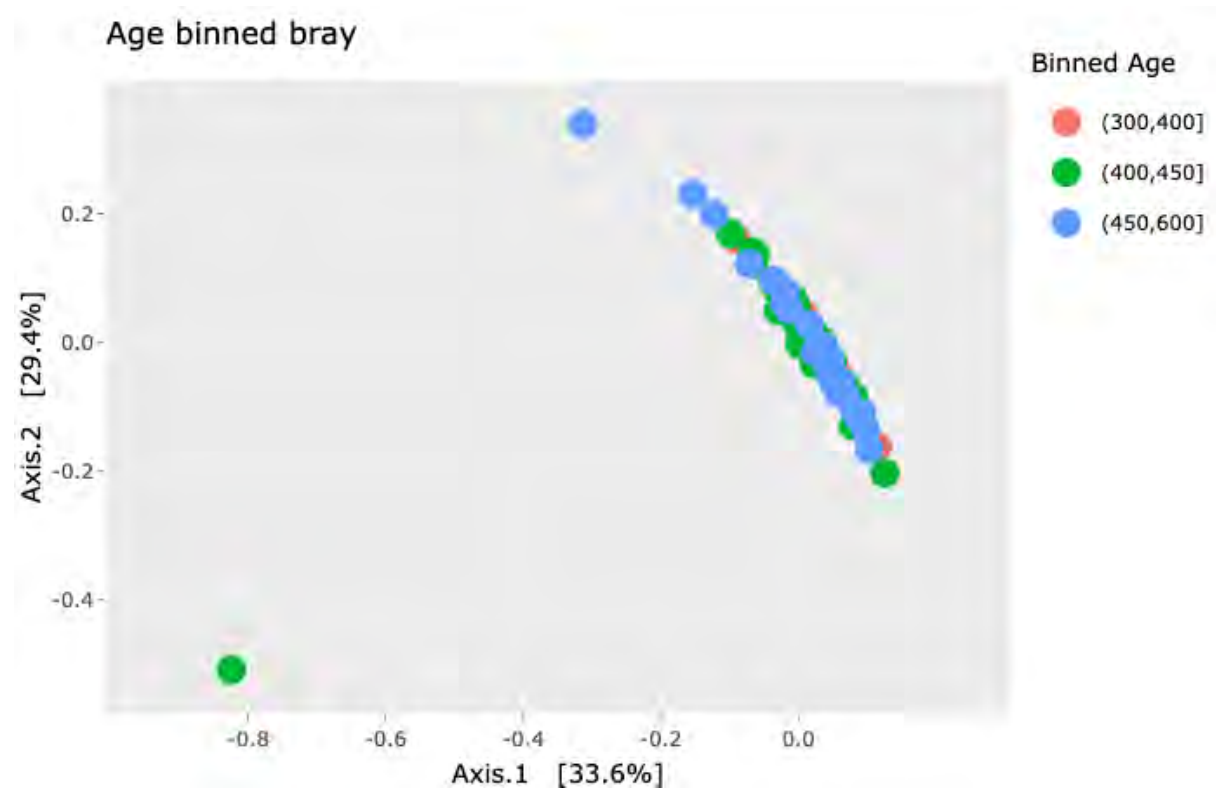

Figura 20. Análise de Coordenadas Principais (PCoA) para idade dos animais. São mostrados 3 grupos de animais clusterizados pela idade em dias. Não é possível evidenciar efeito da idade sobre a composição das populações de arqueas.

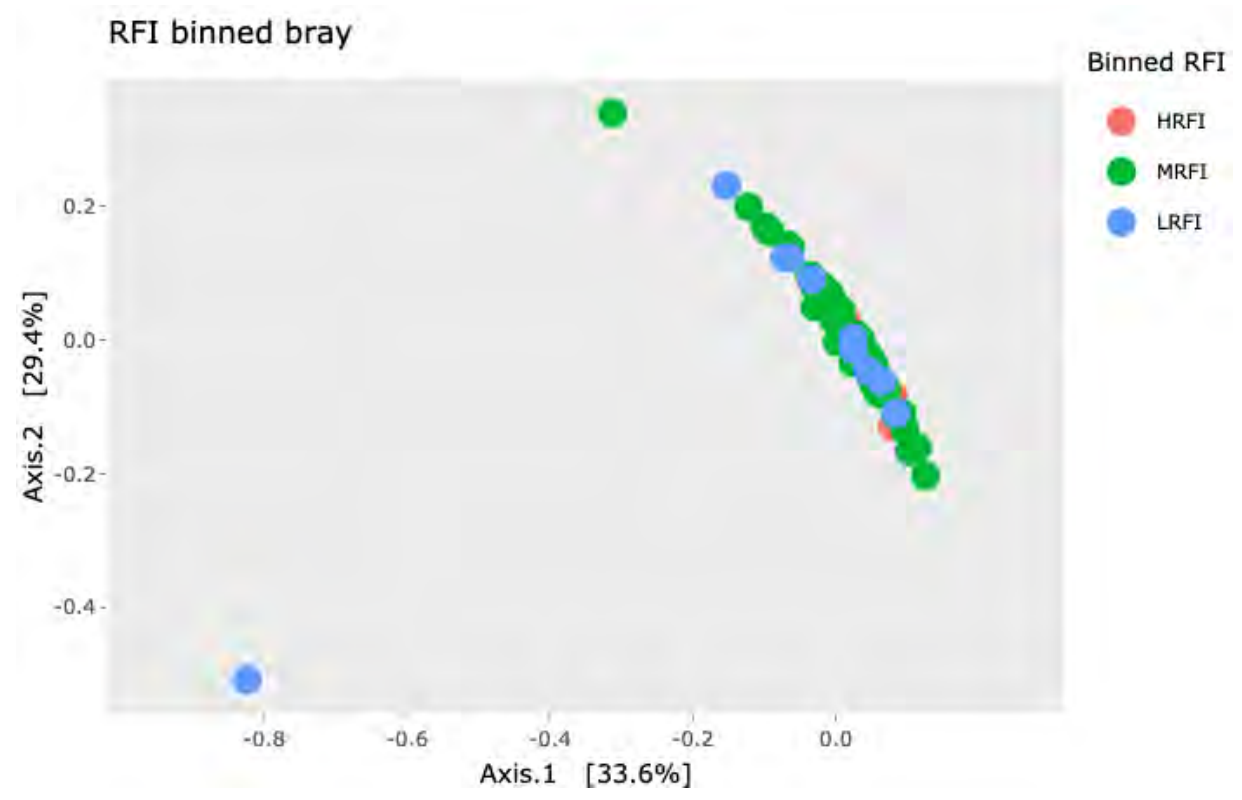

Figura 21. Análise de Coordenadas Principais (PCoA) para CAR (RFI) dos animais. São mostrados 3 grupos de animais clusterizados pelo CAR. Não é possível evidenciar efeito do CAR sobre a composição das populações de arqueas. 


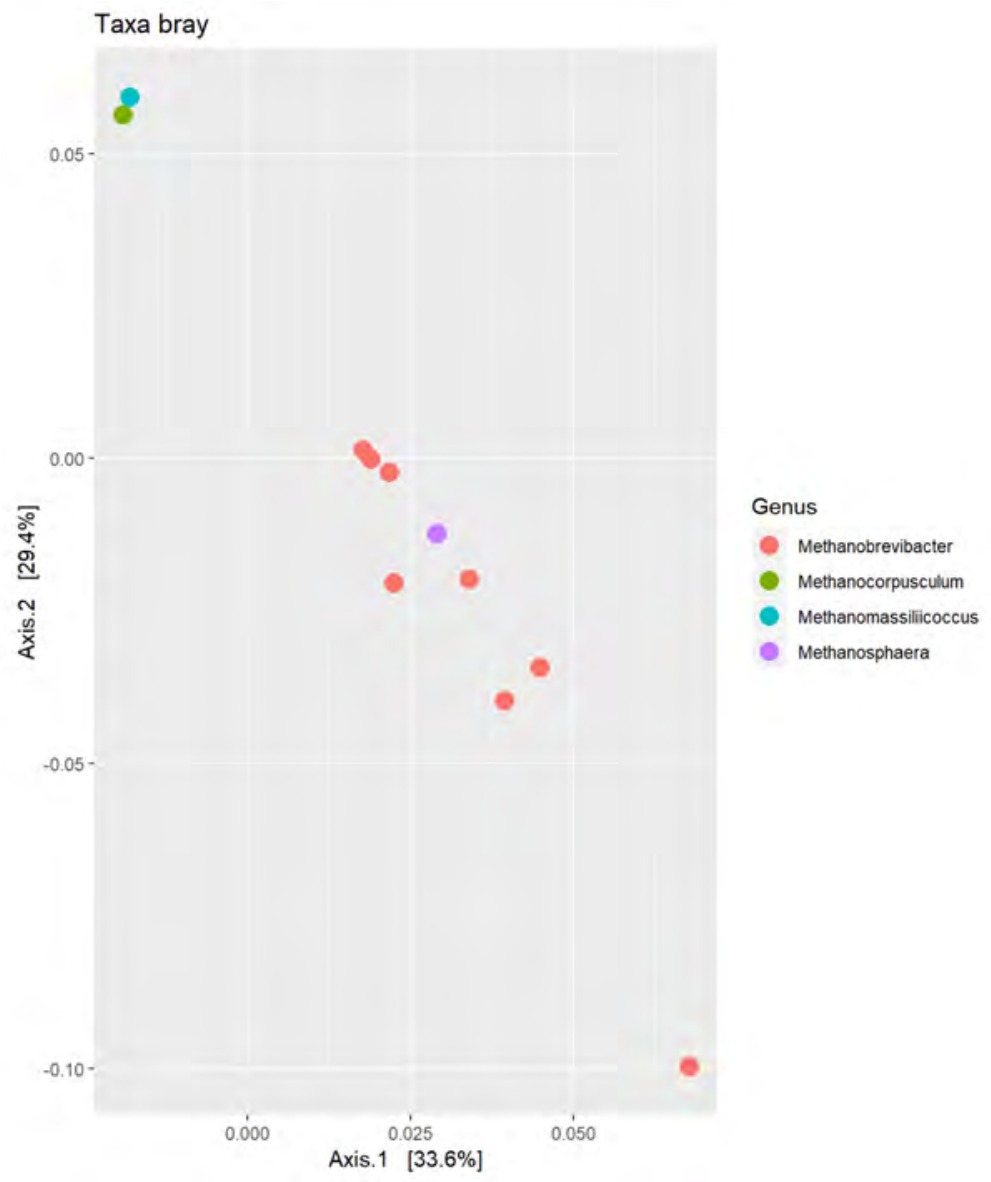

Figura 22. Análise de Coordenadas Principais (PCoA) para os principais gêneros encontrados.

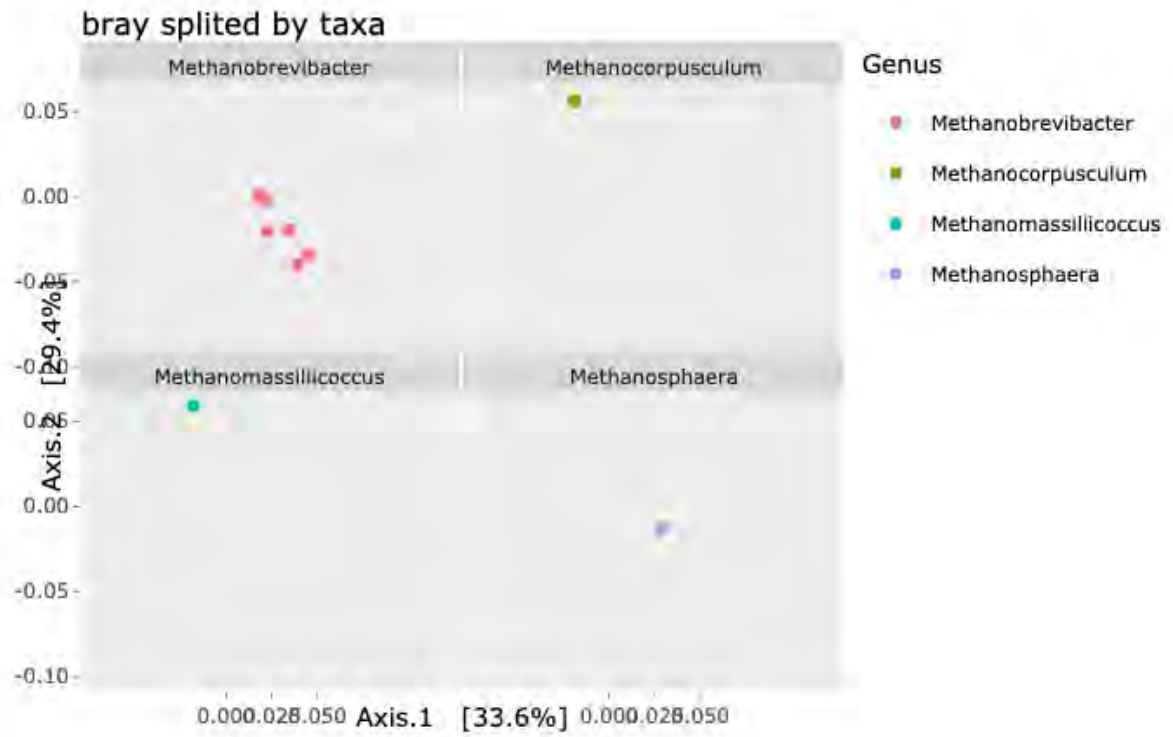

Figura 23. Análise de Coordenadas Principais (PCoA) para os principais gêneros encontrados. É possível notar certa aglomeração de amostras de mesmo gênero pelo PCoA. 
A diversidade alfa foi analisada pelo índice de Shannon que demonstra o quão diferente é a abundância dos micro-organismos nas amostras. Esta análise foi realizada para CAR, idade e lote de animais e nenhuma correlação significativa foi encontrada entre estes parâmetros e a diversidade alfa (Figuras 24, 25 e 26).

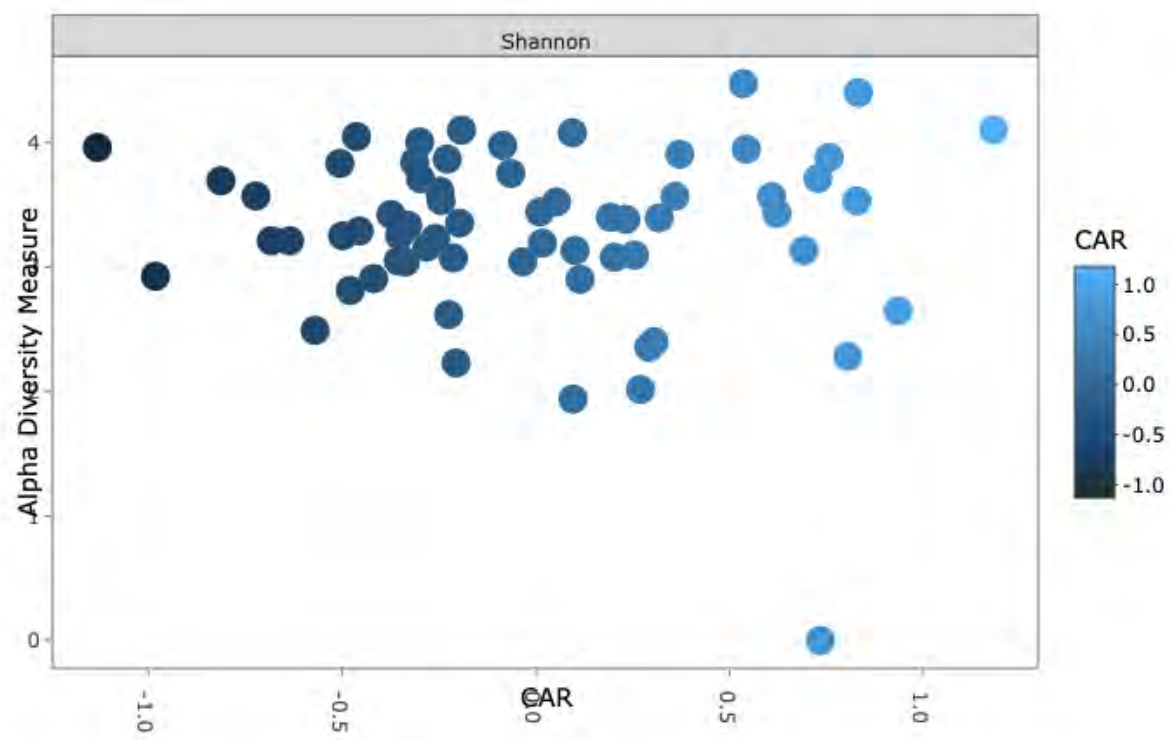

Figura 24. Análise de Diversidade alfa (Shannon) e CAR. Nenhuma correlação foi evidenciada entre estes parâmetros.

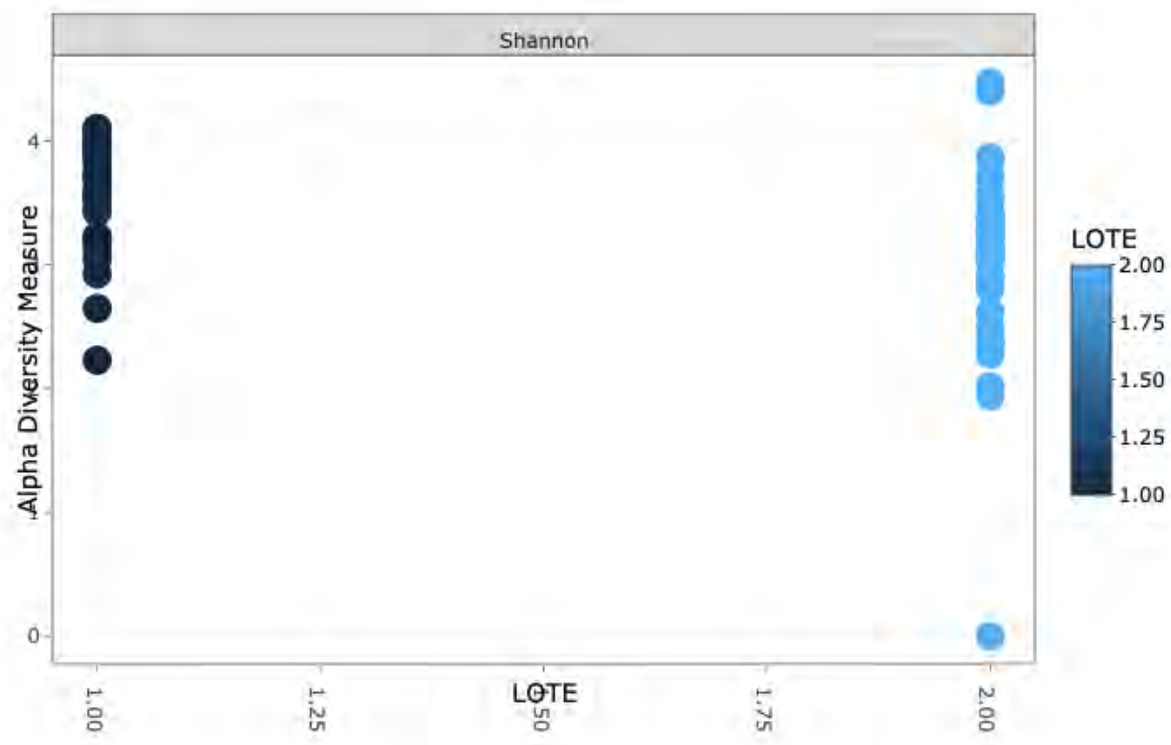

Figura 25. Análise de Diversidade Alfa (Shannon) e lote. Nenhuma correlação foi evidenciada entre estes parâmetros. 


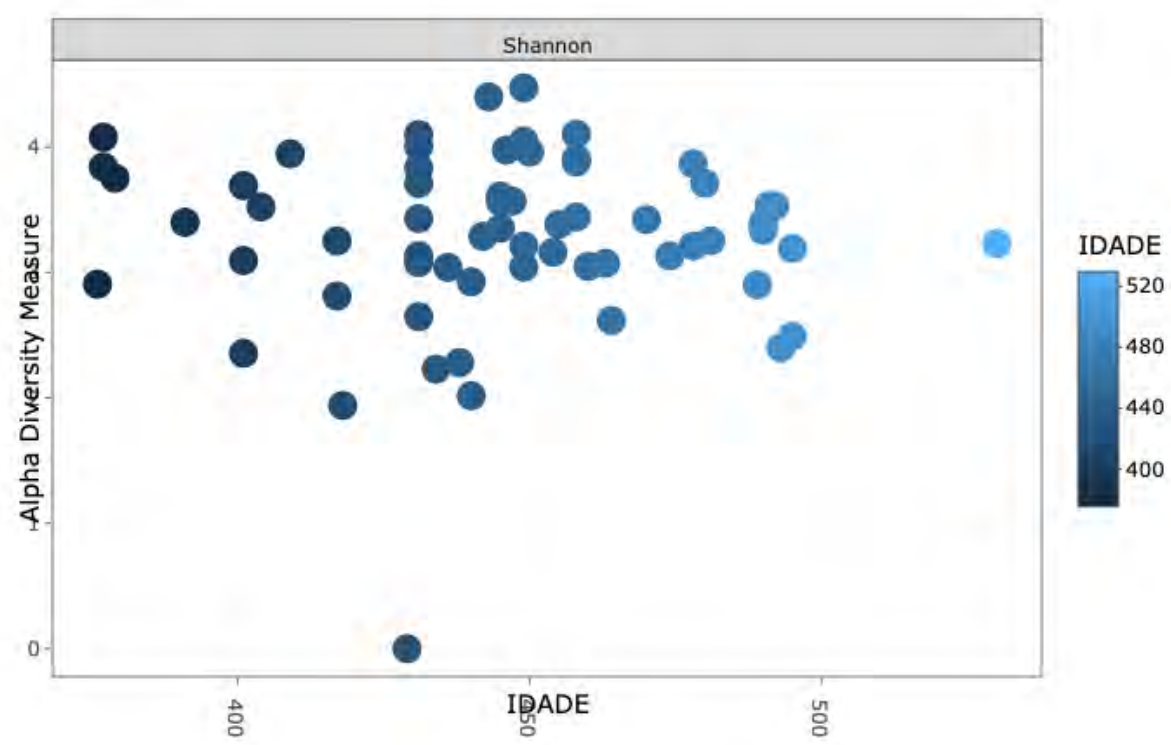

Figura 26. Análise de Diversidade alfa (Shannon) e idade. Nenhuma correlação foi evidenciada entre estes parâmetros. 
$\mathrm{Na}$ figura 27 estão apresentadas as abundâncias relativas por espécie nas amostras experimentais classificadas pelo CAR (>CAR para < CAR).

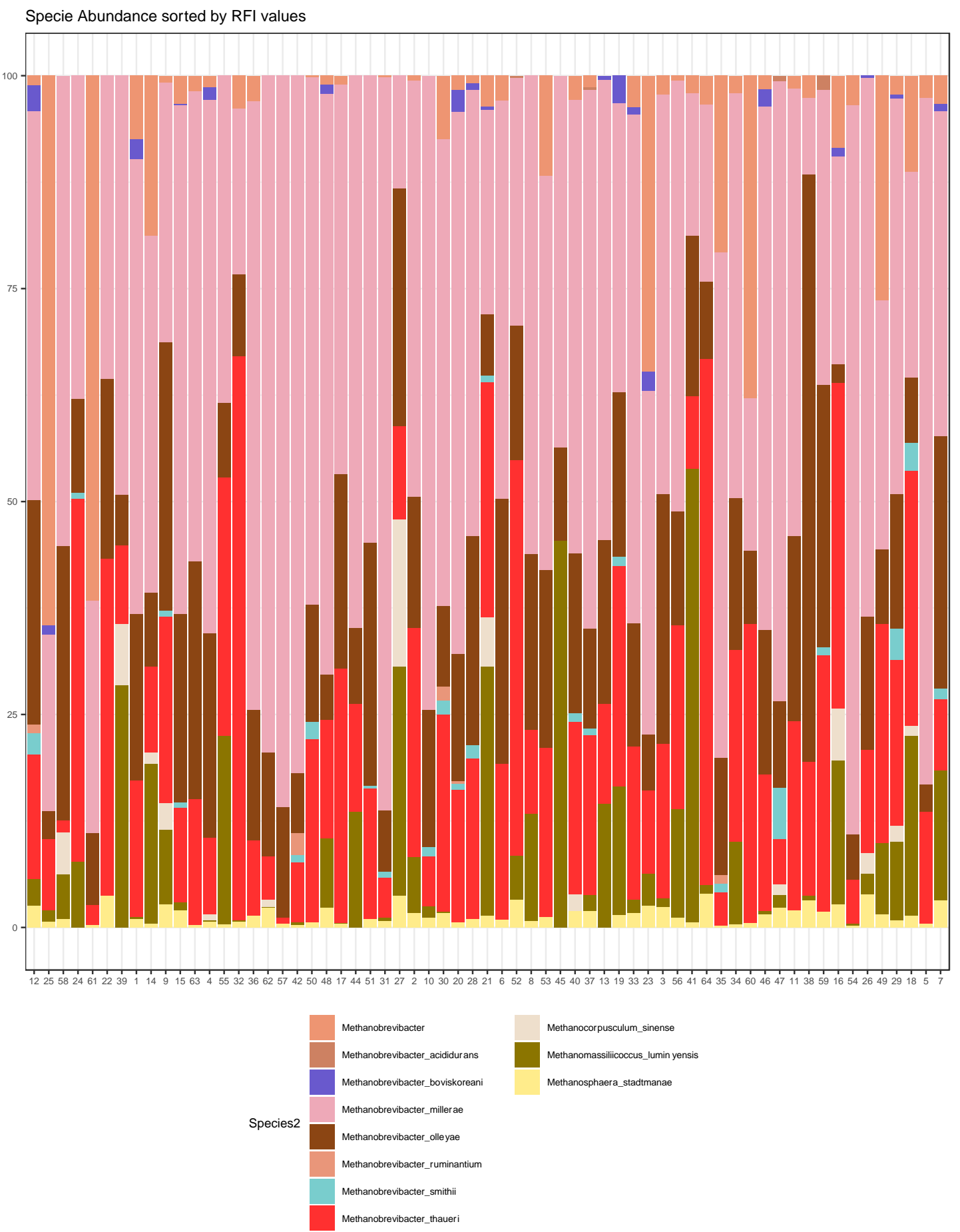

Figura 27. Abundância relativa das espécies nas amostras experimentais. Amostras classificadas do maior CAR para o menor CAR. 
Por fim a abundância relativa específica associada ao CAR e a CA foi analisada de duas maneiras: uma considerando todas as amostras no modelo estatístico considerando-se também a idade e o lote dos animais e uma segunda análise comparativa entre os grupos de alto e baixo CAR e alta e baixa CA.

$\mathrm{Na}$ primeira análise foi possível identificar 3 micro-organismos associados significativamente ao CAR considerando-se $p<0,05$ (Tabela 14) e 3 microorganismos associados significativamente a CA (Tabela 16). Ressalta-se que em ambas análises, as Arquéias metanogênicas são encontradas associadas ao grupo de baixa eficiência alimentar, ou seja, há maior presença destas em animais menos eficientes. Quando a análise foi feita por grupos de alto e baixo CAR e CA, observou-se apenas 1 micro-organismo diferentemente abundante entre os grupos sendo para o CAR o Methanocorpusculum sinense, encontrado em maior quantidade no grupo de baixa eficiência e para a CA um Methanobrevibacter sp., encontrado em maior quantidade no grupo de menor conversão alimentar (Tabelas 15 e 17). 
Tabela 14. Micro-organismos significativamente associados ao CAR

\begin{tabular}{|c|c|c|c|c|c|c|c|}
\hline Classe & Ordem & Família & Gênero & Espécie & LogFC & Valor de P & Valor de P aj \\
\hline Methanobacteria & Methanobacteriales & Methanobacteriaceae & Methanosphaera & Methanosphaera_stadtmanae(CP000102) & 1,2059 & 0,0389 & 0,1612 \\
\hline Methanobacteria & Methanobacteriales & Methanobacteriaceae & Methanobrevibacter & Methanobrevibacter_acididurans(AF242652) & 1,2039 & 0,0431 & 0,1612 \\
\hline Methanobacteria & Methanobacteriales & Methanobacteriaceae & Methanobrevibacter & Methanobrevibacter_smithii(U55233) & 1,7042 & 0,0440 & 0,1612 \\
\hline
\end{tabular}

Tabela 15. Micro-organismo significativamente diferente entre os grupos de alto e baixo CAR

\begin{tabular}{|c|c|c|c|c|c|c|c|}
\hline Classe & Ordem & Família & Gênero & Espécie & $\log F C$ & Valor de $\mathrm{P}$ & Valor de P aj \\
\hline Methanomicrobia & Methanomicrobiales & Methanocorpusculaceae & Methanocorpusculum & Methanocorpusculum sinense(FR749949) & 3,1815 & 0,0081 & 0,0890 \\
\hline
\end{tabular}

Tabela 16. Micro-organismos significativamente associados a CA.

\begin{tabular}{|c|c|c|c|c|c|c|c|}
\hline Classe & Ordem & Família & Gênero & Espécie & $\log \mathrm{FC}$ & Valor de $\mathrm{P}$ & Valor de P aj \\
\hline Methanomicrobia & Methanomicrobiales & Methanocorpusculaceae & Methanocorpusculum & Methanocorpusculum_sinense(FR749949) & 1,7826 & 0,0031 & 0,0810 \\
\hline Methanobacteria & Methanobacteriales & Methanobacteriaceae & Methanobrevibacter & Methanobrevibacter_boviskoreani(KC608769) & 1,2707 & 0,0152 & 0,1981 \\
\hline Thermoplasmata & Methanomassiliicoccales & Methanomassiliicoccaceae & Methanomassiliicoccus & Methanomassiliicoccus_luminyensis(HQ896499) & 1,2734 & 0,0365 & 0,3162 \\
\hline
\end{tabular}

Tabela 17. Micro-organismos significativamente diferente entre os grupos de alta e baixa CA.

\begin{tabular}{|c|c|c|c|c|c|c|c|}
\hline Classe & Ordem & Família & Gênero & Espécie & $\log \mathrm{FC}$ & Valor de $\mathrm{P}$ & Valor de $\mathrm{P}$ aj \\
\hline Methanobacteria & Methanobacteriales & Methanobacteriaceae & Methanobrevibacter & Methanobrevibacter_millerae(AY196673) & 20,8527 & $2,71 \mathrm{E}-07$ & $7,05 \mathrm{E}-06$ \\
\hline Methanobacteria & Methanobacteriales & Methanobacteriaceae & Methanobrevibacter & Methanobrevibacter_olleyae(AY615201) & 17,2139 & $2,13 \mathrm{E}-06$ & $2,76 \mathrm{E}-05$ \\
\hline Methanobacteria & Methanobacteriales & Methanobacteriaceae & Methanobrevibacter & Methanobrevibacter_thaueri(U55236) & 13,1893 & 0,0120 & 0,1042 \\
\hline Methanobacteria & Methanobacteriales & Methanobacteriaceae & Methanobrevibacter & Methanobrevibacter_smithii(U55233) & 16,2492 & 0,0221 & 0,1193 \\
\hline Methanobacteria & Methanobacteriales & Methanobacteriaceae & Methanobrevibacter & Methanobrevibacter_millerae(AY196673) & 18,8740 & 0,0229 & 0,1193 \\
\hline
\end{tabular}




\section{Discussão}

A eficiência alimentar (EA) em bovinos de corte é uma característica para o quão bem o animal utiliza os nutrientes da alimentação para a produção e identifica animais de maior produção em relação aos demais mantendo os mesmos níveis de ingestão de alimento. $O$ objetivo este trabalho foi identificar perfis específicos de micro-organismos associados a esse fenótipo por meio do estudo da microbiota fecal de animais com alta (AEA) e baixa (BEA) eficiência alimentar, que possam esclarecer os processos biológicos envolvidos no aproveitamento de nutrientes desses animais e possibilitem o desenvolvimento de um método de avaliação menos invasiva e uma identificação precoce de indivíduos superiores. Para isso, foram avaliadas diversas medidas fenotípicas relacionadas ao desempenho dos animais em confinamento, bem como dados da microbiota fecal de animais de AEA e BEA, que serão discutidos nas linhas a seguir.

Primeiramente foi realizada a análise de estatística descritiva básica para todos os 64 animais dos fenótipos observados durante o experimento. Foram calculados, média, desvio-padrão, mínimo e máximo do peso inicial, peso final, ganho de peso, ingestão de matéria seca e medidas de eficiência alimentar. Ao serem avaliados os dados de desempenho em confinamento (Tabela 3), percebeu-se que os valores de desvio padrão para conversão alimentar (CA) e consumo alimentar residual (CAR) indicam que existe variação dentro da população estudada para medidas de EA, mostrando que os animais podem ser selecionados para essas características. Esse resultado está de acordo com trabalhos anteriores que avaliaram EA em bovinos Nelore (GOMES et al., 2013; SANTANA et al., 2012, 2013, 2014, ALEXANDRE et al 2015).

Observando as correlações entre os fenótipos de peso vivo inicial (PVI) e final (PVF), ingestão de matéria seca (IMS), ganho de peso médio diário (GMD) e características de EA (Tabela 4), a correlação negativa entre CA e GMD corrobora resultados anteriores tanto em animias taurinos (BASARAB et al., 2003) como 
zebuínos (ALEXANDRE et al., 2015). Isso mostra que animais com baixa CA (mais eficientes de acordo com essa medida) são também os que ganham mais peso. Nota-se que a CA apresentou baixa correlação positiva com PVF, no entanto essa medida de peso não apresentou diferença significativa quando comparada entre grupos de alta e baixa EA. A correlação positiva da CA com PVI pode ser explicada pelo fato de que animais com maior PVI talvez estejam em um estado mais avançado de maturidade, com menor deposição de músculo em relação à quantidade de alimento ingerido. A falta de correlação entre CAR e GMD é esperada, uma vez que o último é utilizado para explicar a variável dependente (IMS) da regressão em que o resíduo corresponde à estimativa do CAR. O mesmo acontece entre CAR e IMS. Por outro lado, também era esperado que o CAR apresentasse alta correlação com IMS.

Observando as correlações entre peso inicial, final, médio e metabólico; ingestão de matéria seca, ganho de peso e medidas de EA com medidas de ultrassonografia de carcaça e (Tabela 6) é possível observar que o peso dos animais está correlacionado com a área de olho de lombo ( $A O L)$, a espessura de gordura na $12^{\underline{a}-13^{\underline{a}}}$ costela (EG), a espessura de gordura na garupa (EGP8) e com a gordura de acabamento ( $A C A B)$, o que já era esperado, umas vez que animais mais pesados tendem a serem maiores. No entanto, a $A O L$ não apresentou correlação com o ganho de peso no período avaliado, o que indica que animais mais pesados não depositaram mais músculo neste período. Os dados de carcaça não apresentam correlação com CAR. Todavia, apresentaram apresentam correlação com o CMS e a EG, EGP8 e o ACAB apresentaram correlação a CA, corroborando com os resultados de diversos trabalhos similares (ARCHER et al., 1999; BASARAB et al., 2003, CARSTENS et al., 2001; HERD et al., 2004; ALEXANDRE et al., 2015).

Posteriormente, os animais divididos em grupos de AEA e BEA foram avaliados quanto à diferença entre a média dos grupos para várias características fenotípicas. Não houve diferença significativa no peso vivo inicial (PVI) e final (PVF) entre os grupos de animais, bem como no desempenho de GMD no período. Todavia, observa-se diferença significativa nas medidas de EA e no IMS, 
sendo esta última menor nos animais de AEA. Esse resultado é consistente com a proposta da medida de CAR ( $\mathrm{KOCH}$ et al., 1963) que visa identificar animais que ingerem menos alimento mantendo o ganho de peso, e estão de acordo com outros estudos em Bos indicus e Bos taurus (ARTHUR; RENAND; KRAUSS, 2001; GOMES et al., 2013; SANTANA et al., 2013; ALEXANDRE et al., 2015).

Quando foram analisadas novamente as medidas de ultrassonografia de carcaça, agora considerando os grupos de AEA e BEA, verificou-se o mesmo já indicado pela análise de correlação. Não houve diferença significativa entre os dois grupos para nenhuma das medidas.

Quanto aos resultados do sequenciamento, no que diz respeito aos perfis de bactéria, foram identificados 21 filos com grande variação de abundância relativa, sendo que os três filos mais predominantes foram Firmicutes, Bacteroidetes, e Proteobacteria, corroborando com estudos similares de eficiência alimentar e microbiota gastrointestinal de ruminantes (JAMI et al., 2014; SHABAT et al., 2016; MYER et al., 2015, 2017; DELGADO et al, 2019) e eficiência alimentar e microbiota fecal de suínos (VERSCHUREN et al., 2018). Membros dos dois primeiro filos (Firmicutes e Bacteroidetes) participam ativamente do processo de degradação de cellulose, juntamente com a bactéria Fibrobacter succinogenes (Filo Fibrobacter), promovendo a quebra das moléculas de celulose e a liberação de açucares fermentáveis que são convertidos em ácidos orgânicos voláteis, os quais serão absorvidos pelo epitélio ruminal (RUSSELL e RYCHLIK, 2001). Quanto ao filo Proteobacteria, é o maior filo bacteriano reconhecido atualmente, os membros são Gram negativos e desempenham uma variedade de papéis, sendo comumente caracterizados na microbiota fecal de mamíferos saudáveis (MOON et al., 2018). Embora possua uma má reputação, devido a presença de membros patógenos oportunistas e espécies associadas a disbiose em hospedeiros com desordens metabólicas e inflamatórias (KIL \& SWANSON, 2011; MOON et al., 2018) o filo Proteobacteria abriga um subgrupo funcional de bactérias metanotróficas, conhecidas por sua habilidade em utilizar o metano como fonte de carbono e energia (LINHARES, 2012). 
Os dados foram analisados quanto à diversidade Beta utilizando o "Weighted Unifrac" para evidenciar efeitos da idade, CAR e filos taxonômicos pela análise de coordenadas principais (PCoA). O Weighted unifrac é uma medida de distância e se baseia na abundância de espécies, levando em consideração a aproximação filogenética entre os animais, ou seja, é verificada a abundância das bactérias de filogenia próxima e essa medida é ponderada pelo número de espécies. Não foi possível evidenciar agrupamentos específicos das amostras por esta análise para idade e CAR como pode ser visto nas figuras 3 e 4 . Já a análise de PCoA para os diferentes filos demonstrou que estes se agrupam por similaridade genética, conforme esperado (Figuras 5 e 6 ).

A diversidade alfa foi analisada pelo índice de Shannon que demonstra 0 quão diferente é a abundância dos micro-organismos nas amostras. A visualização dos índices de diversidade foi realizada para verificar uma eventual influência do CAR, CA, idade e lote de animais na diversidade. Como esperado, não foi encontrado efeito de idade e lote na diversidade de micro-organismos das amostras. De mesmo modo, não foram observada diferenças significativas na abundância relativa e consequente diversidade das amostras classificadas por grupos de EA, resultado. Esse resultado difere do encontrado por Shabat et al (2016) em que foi relatada menor diversidade e maior dominância na composição taxonômica aparente nos microbiomas de animais eficientes e o contrário pode ser observado para o grupo de alto CAR. Os autores justificaram os achados em função do uso mais diversificado de compostos como proteínas dietéticas, piruvato, acetil-CoA e hidrogênio pelos animais ineficientes, que resultaram em um conjunto mais diversificado de metabólitos produzidos, alguns dos quais afetam a energia de forma negativa ou não pode ser utilizada pelo animal para seus requisitos de energia. Nos microbiomas dos animais eficientes, o uso desses compostos é dominado por um número limitado de caminhos metabólicos mais relevantes e valiosos para as necessidades energéticas do animal (KANEHISA et al., 2011). Todavia, os trabalhos acima citados realizaram estudos mais aprofundados de metagenômica completa e expressão gênica que permitem identificar os micro-organismos que exercem função ativa e suas principais vias 
metabólicas. Deste modo, fazem-se necessários estudos mais aprofundados da microbiota fecal para identificar diferenças na diversidade das amostras. O mesmo pode ser explicado para os gráficos de abundâncias relativas por reino, filo, classe, ordem, família, gênero e espécie nas amostras experimentais onde, embora possa ser notada variação populacional nas amostras experimentais classificadas por valor de CAR não há um padrão de abundância que possa ser relacionado com essa característica.

Em contrapartida, nosso estudo identificou diferenças significativas para os grupos de AEA e BEA nas análises da abundância relativa específica associada ao CAR e a CA, realizada de duas maneiras: uma considerando todas as amostras ( $n=64)$ no modelo estatístico considerando-se também o pai, a idade e o lote dos animais e uma segunda análise comparativa entre os grupos de alto e baixo CAR e alta e baixa CA..

É interessante ressaltar que na análise por grupo de CAR, as espécies do filo Bacteroidetes tiveram abundância relativa específica associada apenas a valores positivos de logFC, estes valores caracterizam o grupo de animais de BEA e estes resultados confirmam dados de estudos anteriores onde este mesmo filo foi relacionado à baixa eficiência alimentar (RUSSELL e RYCHLIK, 2001; JAMI et al., 2014; MYER et al., 2015, 2017). Este filo também esteve relacionado à perda de peso em estudos de obesidade realizados com ratos (LEY et al., 2005). Já para a análise por grupo de CA, as espécies deste filo tiveram abundância relativa específica associada apenas a valores negativos de logFC, estes valores caracterizam o grupo de animais de AEA e estes resultados corroboram com os achados mais recentes de Delgado e colaboradores (2019).

Dentre os 3 principais filos encontrados, relatados na Tabela 8, não foram identificados os filos Firmicutes e Proteobacteria para as análises entre os grupos classificados por CA e o filo Proteobacteria para as análises entre os grupos classificados por CAR. Contudo, espécies do filo Firmicutes tiveram abundância relativa específica associada em sua maioria à valores negativos de logFC para CAR, que caracterizam o grupo de animais de AEA. Estes achados estão de acordo com estudos similares de microbiota, onde animais eficientes apresentam 
maiores valores de abundância relativa de bactérias do filo Firmicutes (RUSSELL e RYCHLIK, 2001; JAMl et al., 2014; MYER et al., 2015, 2017; DELGADO et al, 2019). Este filo também foi associado à obesidade em estudos de microbiota intestinal em ratos (LEY et al., 2005)

Quando analisados micro-organismos que apresentaram diferença significativa em ambas as análises apenas o micro-organismo Eubacterium sp. foi associado ao CAR e com relação ao CA apenas o microrganismo Bacteroides sp. apresentou diferença significativa. Ambos os gêneros pertencem ao filo Bacteroidetes. Em estudos similares uma correlação positiva entre Eubacterium sp. e baixa eficiência alimentar foi relatada por Hernandez-Sanabria et al. (2012). Quanto ao gênero Bacteroides sp., este foi predominantemente encontrado em fezes de bezerros pós-desmama e foi negativamente correlacionado relacionados com peso corporal $(-0,45)$ e ingestão de forragem $(-0,32)$ (MEALE et al., 2016).

Quanto aos resultados do sequenciamento, no que diz respeito aos perfis de Arquéias, foram identificados 19 filos com grande variação de abundância relativa, sendo mantidos para análise posteriores apenas os filos Euryarcheota e Thaumarchaeota.

Também pela análise Weighted unifrac, citada anteriormente, não foi possível evidenciar agrupamentos específicos das amostras para idade e CAR como pode ser visto nas figuras 20 e 21. Já a análise de PCoA para os diferentes filos demonstrou que estes se agrupam por similaridade genética, conforme esperado (Figuras 22 e 23).

Assim como as análises realizadas para bactérias nosso estudo também identificou diferenças significativas para os grupos de AEA e BEA nas análises da abundância relativa específica associada ao CAR e a CA, realizada de duas maneiras: uma considerando todas as amostras $(n=64)$ no modelo estatístico considerando-se também o pai, a idade e o lote dos animais e uma segunda análise comparativa entre os grupos de alto e baixo CAR e alta e baixa CA. $\mathrm{Na}$ primeira análise foi possível identificar 3 micro-organismos com abundância significativa relacionadas à animais com valores de logFC positivos (ineficientes) e 3 micro-organismos com abundância significativa relacionadas à animais com 
valores de logFC altos positivos (de 13,19 a 20,85 ) para CA que representam os animais de baixa eficiência alimentar (Tabelas 14 e 16). Quando a análise foi feita por grupos, observou-se apenas 1 micro-organismos com diferença significativa para os grupos de alto e baixo CAR e 5 micro-organismos diferentemente abundante entre os grupos de alto e baixo CA (Tabelas 15 e 17).

Quando analisados micro-organismos que apresentaram diferença significativa em ambas as análises apenas o microrganismo Methanocorpusculum sinense foi associado ao CAR, encontrado em maior quantidade no grupo de baixa eficiência. Com relação ao CA nenhum microrganismo apresentou valores de significância. Ressalta-se que nas análises por grupos de alta e baixa EA tanto para CAR quanto para $C A$, as Arquéias metanogênicas são encontradas associadas inversamente à eficiência alimentar, ou seja, há maior presença destas em animais menos eficientes e estes achados corroboram com estudo de Delgado e colaboradores (2019). No entanto, vale salientar que a estrutura da comunidade metanogênica detectada através de análise de DNA nem sempre indica diferenças na emissão de metano, uma vez que isso deve ser determinado ao nível de expressão gênica e não ao nível de estrutura de comunidade como observado por Jeyanathan et al. (2011). 


\section{CONCLUSÃO}

Os animais de baixa eficiência alimentar apresentam maior ingestão de matéria seca e deposição de gordura, além de apresentarem maiores quantidade de bactérias do filo Bacteoidetes e de arquéias metanogênicas. O microbioma fecal demonstrou ter associação com a eficiência alimentar sendo uma ferramenta menos invasiva que pode ser utilizada na identificação precoce de animais superiores para a eficiência alimentar. 


\section{REFERÊNCIAS}

ABIEC - Associação Brasileira das Indústrias Exportadoras de Carne. Beef REPORT - Perfil da Pecuária no Brasil 2019. Disponível em: http://www.abiec.com.br/controle/uploads/arquivos/sumario2019portugues.pdf Acesso em: 12 de Julho de 2019.

ALEXANDRE, P. A. Caracterização do perfil de expressão gênica hepática global associada à eficiência alimentar em bovinos Nelore. 2015. $143 \mathrm{f}$. Dissertação (Mestrado) - Faculdade de Zootecnia e Engenharia de Alimentos, Universidade de São Paulo, Pirassununga, 2015.

ALFORD, A. R.; HEGARTY, R. S.; PARNELL, P. F.; CACHO, O. J.; HERD, R. M.; GRIFITH, G. R. The impact of breeding to reduce residual feed intake on enteric methane emissions from the Australian beef industry. Australian Journal of Experimental Agriculture, v. 46, p. 813-820. 2006.

ARCHER, J. A. et al. Optimum postweaning test for measurement of growth rate, feed intake, and feed efficiency in british breed cattle. Journal of Animal Science, v. 75, p. 2024-32, 1997.

ARCHER, J. A. et al. Potential for selection to improve efficiency of feed use in beef cattle: a review. Australian Journal of Agricultural Research, v. 50, p. 147162, 1999.

ARONESTY, E. Ea-utils:Command-line tools for processing biological sequencing. Disponível em: <https://expressionanalysis.github.io/ea-utils/>. Acesso em: 14 de Janeiro de 2018.

BASARAB, J. A.; PRICE, M. A.; AALHUS, J. L.; OKINE, E. K.; SNELLING, W. M.; LYLE, K. L.. Residual feed intake and body composition in young growing cattle. Canadian Journal of Animal Science, v. 83, p. 189-204, 2003.

BASARAB, J. A.; BEAUCHEMIN, K. A.; BARON, V. S.; OMINSKI, K. H.; GUAN, L. L.; MILLER, S. P.; CROWLEY, J. J. Reducing GHG emissions through genetic improvement for feed efficiency: effects on economically important traits and enteric methane production. Animal. v. 7, n. 2, p. 303-315, 2013.

BEAUCHEMIN, K. A.; JANZEN, H.; LITTLE, S. M.; MCALLISTER, T. A.; MCGINN, S.M. Life cycle assessment of greenhouse gas emissions from beef production in western Canada: A case study. Agricultural Systems, v. 103, p. 371-379, 2010

BEAUCHEMIN, K. A.; MCALLISTER, T. A.; MCGINN, S. M. Dietary mitigation of enteric methane from cattle. CAB Reviews: Perspectives in Agriculture, Veterinary Science, Nutrition and Natural Resources 4, No. 35, 2009. 
BRASIL - Ministério da Agricultura, Pecuária e Abastecimento. Projeções do Agronegócio - Brasil 2016/17 a 2026/27. Projeções de Longo Prazo. 8a ed. 125p. Brasília/DF, 2017.

BRULC, J. M.; ANTONOPOULOS, D. A.; MILLER, M. E. B.; WILSON, M. K.; YANNARELL, A. C.; DINSDALE, E. A.;COUTINHO, P. M. Gene-centric metagenomics of the fiber-adherent bovine rumen microbiome reveals forage specific glycoside hydrolases. Proceedings of the National Academy of Sciences, V. 106, P. 1948-1953, 2009.

CARBERRY, C. A.; KENNY, D. A.; HAN, S.; MCCABE, M. S.; WATERS, S. M. Effect of phenotypic residual feed intake and dietary forage content on the rumen microbial community of beef cattle. Applied and Environmental Microbiology, v. 78, p. 4949-4958, 2012.

CARSTENS, G. E. Net feed intake: Potential selection tool to improve feed efficiency in beef cattle. Departament of Animal Science. Texas A\&M University, 2001.

CARTENS, G. E.; TEDESCHI, L. O. Defining feed efficiency in beef cattle. Proceedings of the Beef Improvement Federation 38th Annual Research Symposium and Annual Meeting. Choctow, MS, EUA, p. 12-21, abr.2006.

CEDERBERG, C.; PERSSON, M.; NEOVIUS, K.; MOLANDER, S.; CLIFT, R. Including carbon emissions from deforestation in the carbon footprint of Brazilian beef. Environmental Science and Technology, v. 45, p. 1773-1779, 2011

CHANNON, A. F.; ROWE, J. B.; HERD. R. M. Genetic variation in starch digestion in feedlot cattle and its association with residual feed intake. Australian. Journal of Experimental Agriculture, v. 44, p. 469-474, 2004

COOK, G. M.; RAINEY, F. A.; CHENG, S.; TACKEBRAND, T.E.; RUSSELL, J. B. Emendation of the Description of Acidaminococcus fermentans, atrans-Aconitate and Citrate-Oxidizing Bacterium. International Journal of Systematic Bacteriology, v. 44, p. 576-578, 1994.

COTTLE, D.; KAHN, L. Beef Cattle Production and Trade. Australia. CSIRO, 2014.

DELFINO, J. G.; MATHISON, G. E. Effects of cold environment and intake level on the energetic efficiency of feedlot steers. Journal of Animal. Science, v. 69, p. 4577-4587, 1991.

DELGADO, B. et al. Whole rumen metagenome sequencing allows classifying and predicting feed efficiency and intake levels in cattle. Scientific reports, Madrid, jan. 2019. 
DEPENBUSCH, B. E. et al. Influence of processed grains on fecal $\mathrm{pH}$, starch concentration, and shedding of Escherichia coli $\mathrm{O} 157$ in feedlot cattle. Journal of Animal Science, v. 86, p. 632-639, 2008.

FOX, F. G.; GUUIROY, P. J.; TEDESCHI, L. O.; Determining feed intake and feed efficiency of individual cattle fed in groups. Proc. 33rd Beef Improvement Federation meeting, San Antonio, TX. 2001.

FREY, J. C.; PELL, A. N.; BERTHIAUME, R.; LAPIERRE, H.; LEE, S.; MENDELL J. K.; HA, J. E.; ANGERT E. R. Comparative studies of microbial populations in the rumen, duodenum, ileum and faeces of lactating dairy cows. Journal of Applied Microbiology v. 108, p. 1982-1993, 2010.

GENTLEMAN, R. C, et al. Bioconductor: open software development for computational biology and bioinformatics. Genome Biology, V5, 2004.

GOMES, R. C. et al. Protein synthesis and degradation gene SNPs related to feed intake, feed efficiency, growth, and ultrasound carcass traits in Nellore cattle. Genetics and molecular research, Ribeirão Preto, v. 12, n. 3, p. 2923-36, jan. 2013.

GUAN, L. L.; NKRUMAH, J. D.; BASARAB, J. A.; MOORE, S. S. Linkage of microbial ecology to phenotype: correlation of rumen microbial ecology to cattle's feed efficiency. FEMS Microbiology Letters, v. 288 p. 85-91, 2008.

HAYES, B. J.; LEWIN, H. A; GODDARD, M. E. The future of livestock breeding: genomic selection for efficiency, reduced emissions intensity, and adaptation. Trends in Genetics : TIG, v. 29, p. 206-14, 2013.

HERD, R. M.; ARTHUR, P. F. Physiological basis for residual feed intake. Journal of Animal Science. Savoy, v. 87, p. 64-71, 2009.

HERD, R. M.; ODDY, V. H.; RICHARDSON, E. C. Biological basis for variation in residual feed intake in beef cattle. 1. Review of potential mechanisms. Australian Journal of Experimental Agriculture, Collingwood, v. 44, p. 423-430, 2004.

HERNANDEZ-SANABRIA, E.; GOONEWARDENE, L. A.; WANG, Z.; DURUNNA, O. N.; MOORE, S. S.; GUAN, L. L. Impact of feed efficiency and diet on adaptive variations in the bacterial community in the rumen fluid of cattle. Applied and Environmental Microbiology, v. 78, p. 1203-1214, 2012.

HERNANDEZ-SANABRIA, E.; GUAN, L. L.; GOONEWARDENE, L.A.; LI, M.; MEIJU, D. F.; STOTHARD, P.; MOORE, S. S.; LEON-QUINTERO, M. C. Correlation of particular bacterial pcr-denaturing gradient gel electrophoresis patterns with bovine ruminal fermentation parameters and feed efficiency traits. Applied and Environmental Microbiology, v. 76, p. 6338-6350, 2010. 
JAMI, E.; WHITE, B. A.; MIZRAHI, I. Potential role of the bovine rumen microbiome in modulating milk composition and feed efficiency. Plos One, v. 9, e85423, 2014.

JEYANATHAN, J.; KIRS, M.; RONIMUS, R. S.; HOSKIN, S. O.; JANSSEN, P. H. Methanogen community structure in the rumens of farmed sheep, cattle and red deer fed different diets. FEMS Microbiology Ecology, v.76, p. 311-326, 2011.

JOHNSON, D. E.; FERRELL, C. L.; JENKINS, T. G.. The history of energetic efficiency research: Where have we been and where are we going? Journal of Animal Science, v. 81, p. 27-38, 2003.

KANEHISA, M.; GOTO, S.; SATO, Y.; FURUMICHI, M.; TANABE, M. KEGG for integration and interpretation of large-scale molecular data sets. Nucleic Acids Research, v. 40, p. 109-114, 2011.

KHIAOSA-ARD, Q.; ZEBELI, Q. Cattle's variation in rúmen ecology and metabolism and its contributions to feed efficiency. Livestock Science, v. 162, p. 66-75, 2014.

KIL, D. Y.; SWANSON, K. S. Companion Animals Symposium: role of microbes in canine and feline health. Journal of Animal Science, V.89, p. 1498-1505, 2011.

$\mathrm{KOCH}, \mathrm{R} . \mathrm{M}$. et al. Efficiency of feed use in beef cattle. Journal of Animal Science, v. 22, p. 486-494, 1963.

LEY, R.E. et al. Obesity alters gut microbial ecology. Proceedings of the National Academy of Sciences, 102, 11070-11075, USA, 2005

LI, F.; ZHOU, M.; OMINSKI, K.; GUAN, L. Does the rumen microbiome play a role in feed efficiency of beef cattle? Journal of Animal Science. v. 94, n. 6, p. 44-48, 2016.

LINHARES, D. C. Estudo da comunidade metanotrófica em amostras do manguezal de Bertioga, Estado de São Paulo, através da técnica de marcação de ácidos nucléicos com isótopos estáveis (SIP-DNA). 2012. Dissertação (mestrado). 112 f. Instituto de Ciências Biomédicas. Universidade de São Paulo. São Paulo, 2012.

MAO, S. Y.; ZHANG, R. Y.; WANG, D. S.; ZHU, W. Y. Impact of subacute ruminal acidosis (SARA) adaptation on ruminal microbiota in dairy cattle using pyrosequencing. Anaerobe, v. 24, p. 12-19, 2013.

MEALE, S. J. et al. Microbiomes are affected by weaning but not weaning strategy in dairy calves. Frontiers in Microbiology, Canada, v. 7, n.582, mai. 2016. 
MÜLLER, U.; LUETHOLD, G.; REINECKE, P. Prospects of indirect selection against residual feed intake in dairy cattle. Artchir fur Tierzucht, Dummerstorf, v. 38, p. 277-287, 1995.

MYER, P. R.; SMITH, T. P. L.; WELLS, J. E.; KUEHN, L. A.; FREETLY, H. C. Rumen microbiome from steers differing in feed efficiency. Plos One v. 10 e. 0129174, 2015.

MYER, P.R.; FREETLY, H. C.; WELLS, J. E.; SMITH, T. P. L.; KUEHN. Analysis of the gut bacterial communities in beef cattle and their association with feed intake, growth, and efficiency. Journal of Animal Science, v. 95, p.3215-3224, 2017.

MOON, C. D. et al. Metagenomic insights into the roles of Proteobacteria in the gastrointestinal microbiomes of healthy dogs and cats. Microbiology Open, 2018.

NKRUMAH, J. D. et al. Relationships of feedlot feed efficiency, performance, and feeding behavior with metabolic rate, methane production, and energy partitioning in beef cattle. Journal of Animal Science, v. 84, p. 145-53, 2006.

OWENS, F. N.; ZINN, R. A.; KIM, Y. K. Limits to starch digestion in the ruminant small intestine. Jornal of Animal Science, v. 63, p. 1634-1648

POTTS, S. B.; BOERMN, J. P.; LOCK, A. L. ALLEN, M. S. Relationship between residual feed inake and digestibility for lactating Holstein cows fed high and low starch diets. Journal of Dairy Science, v. 100, p. 1-14, 2017.

PRIVE, F.; KADERBHAI, N. N.; GIRDWOOD, S.; WORGAN, H. J.; PINLOCHE, E.; SCOLLAN, N. D.; et al. Identification and Characterization of three novel lipases belonging to families II and V from Anaerovibrio lipolyticus 5ST. Plos One, v. 8, e. 69076, 2013.

RICHARDSON, E.C.; HERD, R. M. Biological basis for variation in residual feed intake in beef cattle. 2. Synthesis of results following divergent selection. Australian Journal of Experimental Agriculture, v. 44, p. 431-440, 2004

ROBINSON, M. D.; MCCARTHY, D. J.; SMYTH, G. K. edgeR: a Bioconductor package for differential expression analysis of digital gene expression data.

Bioinformatics, V.26 n. 1, p.139-140, 2010.

Russell, J. B.; Rychlik, J. L. Factors That Alter Rumen Microbial Ecology. Science, v. 292, 2001.

SAAMA, P.M.; MAO, I. L. Energy intake and gross efficiency comparisons from calorimetric and field data on some lactating cows. Journal of Dairy Science, v. 78, p. 1945-1953, 1995. 
SANTANA, M. H. A. et al. Blood cell and metabolic profile of Nellore bulls and their correlations with residual feed intake and feed conversion ratio. Revista Brasileira de Saúde e Produção Animal, Salvador, v. 14, n. 3, p. 527-537, 2013.

SANTANA, M. H. A. et al. Feed efficiency and its correlations with carcass traits measured by ultrasound in Nellore bulls. Livestock Science, Netherlands, v. 145, n. 1-3, p. 252-257, maio 2012.

SANTANA, M. H. A. et al. Genetic parameter estimates for feed efficiency and dry matter intake and their association with growth and carcass traits in Nellore cattle. Livestock Science, Netherlands, v. 167, p. 80-85, set. 2014

SHABAT, S. K. B.; SASSON1, G.; DORON-FAIGENBOIM, A., DURMAN, T., YAACOBY, S., MILLER, M. E. B.; WHITE, B. A.; SHTERZER, N.; MIZRAHI, I. Specific microbiome-dependent mechanisms underlie the energy harvest efficiency of ruminants. The ISME Journal, v. 10, p. 2958-2972, 2016.

VERGE, X. P. C.; DYER, J. A.; DESJARDINS, R. L. WORTH, D. Greenhouse gas emissions from the Canadian beef industry. Agricultural Systems, v. 98, p. 126134, 2008

VERSCHUREN, L. M. G. et al. Fecal microbial composition associated with variation in feed efficiency in pigs depends on diet and sex. Journal of Animal Science, v.96, p. 1405-1418, 2018.

WONFOR, Ruth. Feed efficiency in ruminants: Impacts on production and the environment. Disponível em: <https://businesswales.gov.wales/farmingcon nect/posts/feed-efficiency-ruminants-impacts-production-and-environment > Acesso em: 14 de fevereiro de 2019.

ZHOU, M.; HERNANDEZ-SANABRIA, E.; GUAN, L. L. Assessment of the microbial ecology of ruminal methanogens in cattle with different feed efficiencies. Applied and Environmental Microbiology, v. 75, p. 6524-6533, 2009. 